IS This document consists of 54 pages, No. $4 / 5$..... of 63 . copies, Series.....A

Date of Issue: July 15, 1953

Report Number: NYO 1355

Subject Category: Technology - Feed Materials
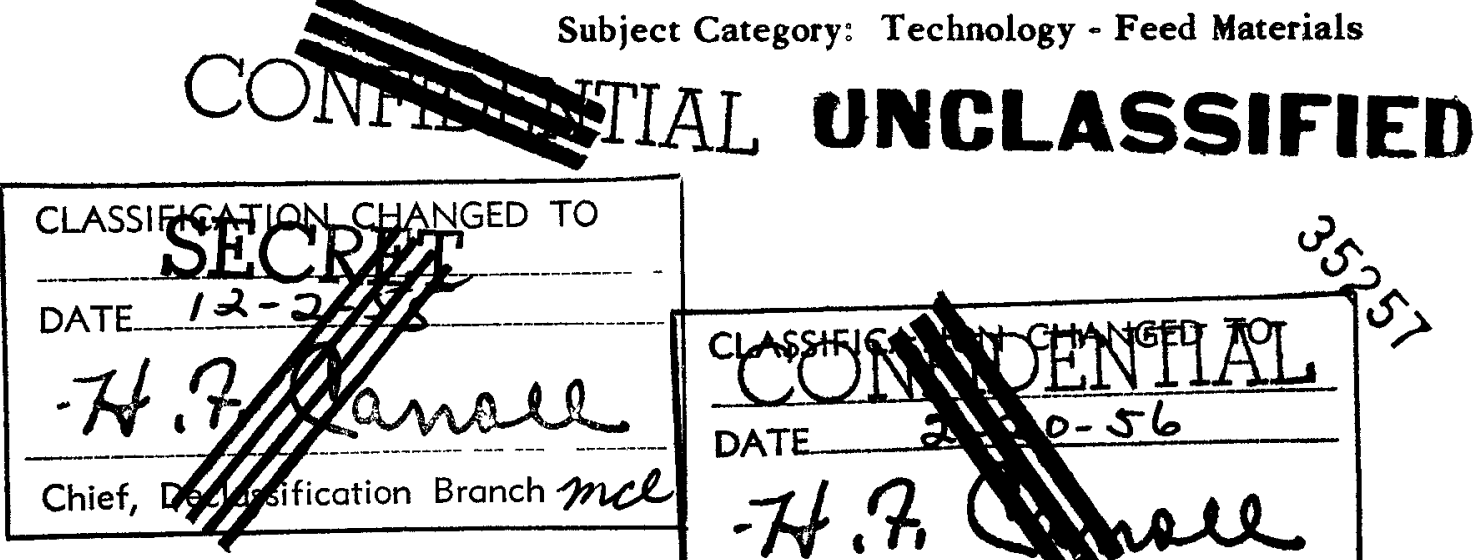

by

A. E. Ruehle and Research Laboratory Personnel

J. U. Shepardson and Analytical Laboratory Personnel
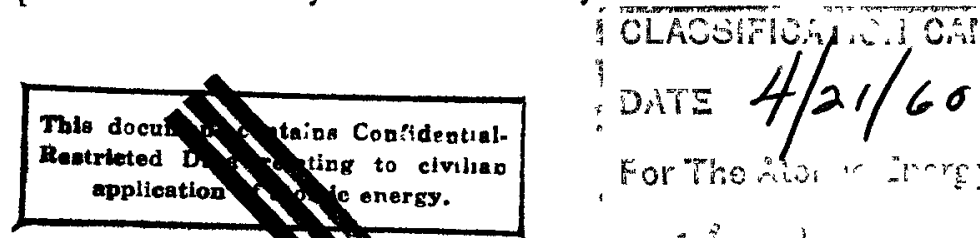

Chief, Declassification Branch Fue

PROCESS DEVELOPMENT QUARTERLY REPORT, PART I

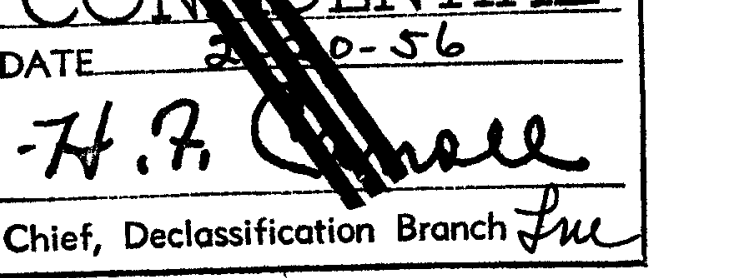

\title{
RESTRICTE DATA
}

This docume ontains restricted data as defined in 1. tomic Energy Act of 1946. Its transm or the disc'osure of its contents in a. vanner to any unauthorized person $\mathbf{X}$ prohibited.

Mallinckrodt Chemical Works

This document is PUBLICLY RBLEASABLE QRO Review Team Authorting Oricial Date $11-9-2010$

St. Louis, Missouri
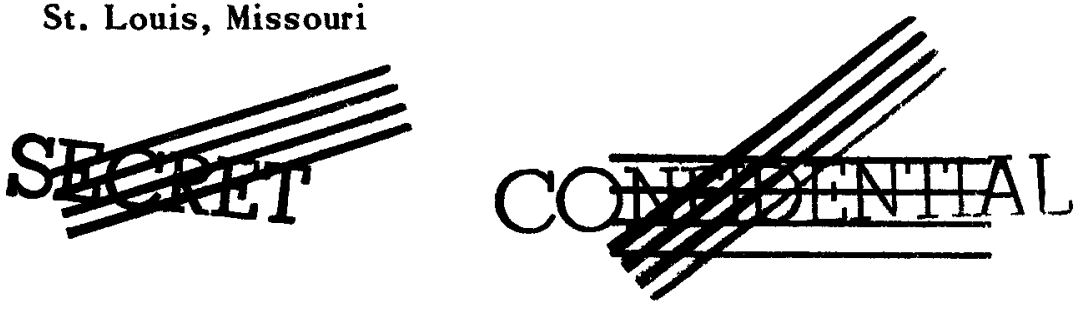

\section{SECURITY IAYFÖRHAAFION}




\section{DISCLAIMER}

This report was prepared as an account of work sponsored by an agency of the United States Government. Neither the United States Government nor any agency Thereof, nor any of their employees, makes any warranty, express or implied, or assumes any legal liability or responsibility for the accuracy, completeness, or usefulness of any information, apparatus, product, or process disclosed, or represents that its use would not infringe privately owned rights. Reference herein to any specific commercial product, process, or service by trade name, trademark, manufacturer, or otherwise does not necessarily constitute or imply its endorsement, recommendation, or favoring by the United States Government or any agency thereof. The views and opinions of authors expressed herein do not necessarily state or reflect those of the United States Government or any agency thereof. 


\section{DISCLAIMER}

Portions of this document may be illegible in electronic image products. Images are produced from the best available original document. 


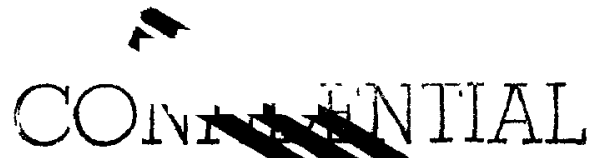

\section{GENERAL INTRODUCTION}

During the second quarter of 1953 laboratory work was divided among raw material processing, plant assistance, and metal quality projects. Evaluation studies of the metal produced in pilot plant experiments were included. $\Lambda$ comparative study of the defects found in ingots and in slugs was started. Significant progress has been made in the development of processes for the recovery of uranium from plant waste streams.

Battelle Institute continued to collaborate with us and was able to contribute materially to our program.

Pilot plant work for this quarter is reported in Process Development Quarterly Report, Part II, NYO 1356.

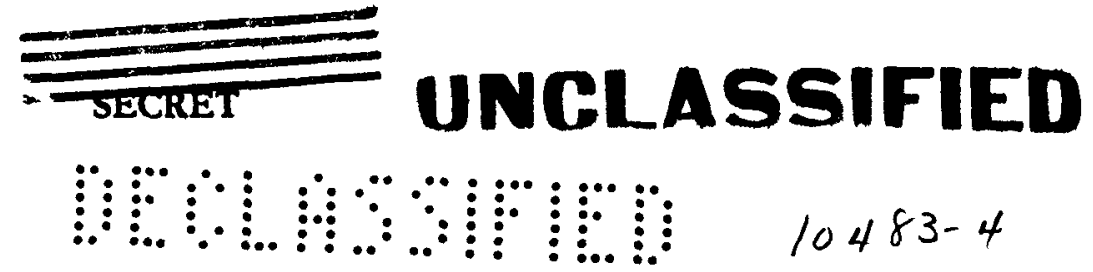




\section{CONCLUSIONS}

1. The Waxco process is adaptable to fixed bed column operation with clear liquors, and to suspended bed countercurrent batch operation with slurries. With TBP.wax the stripping step is slower than extraction, but this might be rectified using warmer strip solutions. Equilibrium studies of the stripping operation are in progress.

2. Emulsions difficulties with Rand ion exchange precipitates may be at least partially alleviated by calcination at $450^{\circ} \mathrm{C}$. Further study of these materials is in progress.

3. The rate of hydrofluorination of $\mathrm{UO}_{2}$ to $\mathrm{UF}_{4}$ is affected by the rate of heating during the denitration of uranyl nitrate to $\mathrm{UO}_{3}$. There is preliminary evidence that the thermal history is important at a much earlier stage in the denitration process than was previously thought.

4. Carbonate leaching of $U$ from slag falls short of remoral to $0.05 \% U_{3} O$, or less. Acid leach processes are successful, but exact details for most economical operation are not yet determined. Prior recovery of $\mathrm{HF}$ can be accomplis hed, but the reactivity of $\mathrm{MgF}_{2}$ slag with $\mathrm{H}_{2} \mathrm{SO}_{4}$ is lower than that of fluorspar.

5. More favorable mold geometry results in greatly improved ingot soundness, as shown by porosity and inclusion studies of larger diameter ingots cast in the pilot plant. Defect studies of slugs indicate that slag inclusions are not the cause of striations, since slag does not conform to the rolling. Oxide inclusions and/or impurities segregated at shrinkage cavities in ingots are more suspect as being responsible for striations found in slugs. "Good crop" metal has been found to contain numerous inclusions, including $\mathrm{MgO}$ (probably from crucible dressing).

Battelle has obtained direct X-ray evidence that "carbide" inclusions are indeed UC. They have also started application of microradiography techniques to the study of derby, ingot, and slug metal.

6. X-ray equipment has been installed at St. Louis and has already proven useful in identification of inclusions in crop metal. Vacuum fusion equipment for determination of oxygen in metal has been built and put into operation.

7. A modification of the method of determination of nitrogen in metal has been studied. $U_{2} N_{3}$ and $\mathrm{UN}$ are not decomposed by $\mathrm{HCl}$ used in the present method. Perchloric acid decomposition results in much higher values in derby metal, while ingot metal values in the normal range are unchanged. 


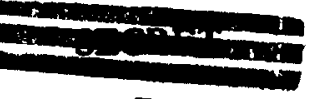

-7 -

8. Spectrographic method developments for improved sensitivity of the boron determination, and for improved sample preparation have been otudied. 


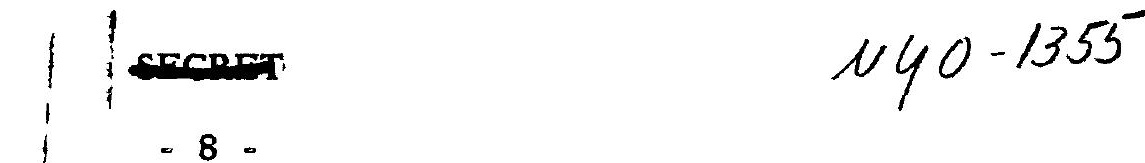

\section{THE WAXCO PROCESS}

by

D. E. Rhodes

\section{Introduction}

The primary emphasis of this project has been to obtain a workable process for the recovery of uranium from the raffinate of the ether extraction system at the St. Louis Refinery. At present two processes indicate considerable promise. One process involves filtering the raffinate and passing it over wax flakes packed in a column. The other process is a batchwise, process using wax flakes directly with the raffinate slurry. A coarse screen, capable of letting the solids through, can be used to separate the wax from the raffinate.

At present both processes are being investigated by the laboratory and the pilot plant.

Tributyl phosphate is the only complexing agent investigated since it appears to be quite satisfactory for the present purpose. It is hoped that other complexing agents can be investigated for use with wax in the near future.

\section{Conclusions}

Tributyl phosphate as high as $50 \%$ by weight can be used with certain waxes.

High melting point microcrystalline waxes $\left(75-95^{\circ} \mathrm{C}\right)$ appear to be satisfactory for use with tributyl phosphate at room temperature.

Capacities as high as $56 \mathrm{mg} \mathrm{U} / \mathrm{g}$ wax have been obtained using batchwise extraction, with indications that even high capacities may be realized.

Equilibrium data indicate advantages for countercurrent stripping of uranium from the wax.

\section{Procedures}

1. Preparation of TBP-wax

The wax mixtures were prepared by melting the wax, adding the TBP, mixing, and pouring into rapidly agitated cold water. This results in flakes of wax which were air-dried prior to use. 
II. Column Operation

The use of wax flakes in glass columns has been described in NYO 1354.

III. Batchwise Operation

Wax flakes were contacted with raffinate slurty in a twelve liter bucket. A Lightnin mixer with a three-bladed agitator near the bottom of the bucket was used to bring fresh solution into contact with the floating wax bed. There was no direct contact between the wax particles and the agitator. Earlier work (NYO 1354) indicated direct contact of the wax with an agitator would tend to break the wax into particles too small for separation from raffinate.

IV. Wax-TBP Equilibrium.Studies

Each run involved $200 \mathrm{ml}$ of uranyl nitrate solution of various concentrations, and $20 \mathrm{~g}$ of wax. The solution and wax were stirred twenty-four hours in a $500 \mathrm{ml}$ Erlenmeyer using a glass agitator. In the present work equilibrium was approached only from one direction, no uranyl nitrate in the wax initially. Eventual study will be from both directions to ascertain that equilibrium is being reached in the specified time.

\section{Analytical}

Uranium analyses were made using an extraction procedure using ten percent tributyl phosphate in ether and a $\mathrm{LiNO}_{3}-\mathrm{HNO}_{3}$ acid solution wash followed by carbonate re-extraction and a carbonate - peroxide reading on a Beckmann Model B spectrophotometer.

\section{Experimental Data and Discussion}

I. Column Study

The column using 30\% TBP in wax as described in NYO 1354 was used to make a single run with a pitchblende raffinate from the Plant. The results are given in Table $\mathrm{I}$. 


\section{Table I}

The Column Extraction of Uranium from Pitchblende

Raffinate Using Tributyl Phosphate in Wax

Conditions:

Flow rate $=0.15 \mathrm{ml} / \mathrm{g} \mathrm{wax} / \mathrm{min}$.
Grams of wax used $=100$ (dry basis)
Composition of wax (by weight)

30\% Tributyl Phosphate

35\% Shell MX-170 Wax

$35 \%$ Glyco Acrawax C

Inside diameter of column $=22 \mathrm{~mm}$

Volume in column occupied by wax $=235 \mathrm{~cm}^{3}$

Original $U$ in raffinate: Series $I-1.58 \mathrm{U} / 1$

Series $11-i . i g ~ U / 1$

No regeneration of wax between Series I and II

Total Volume

Through Column

ml

700

1200

1400

1700

2300
Series 1

$\mathrm{U} \mathrm{g} / \mathrm{I}$

In Effluent

0.06

0.11

0.18

0.41

0.68
Total Volume

Through Column

$\mathrm{ml}$

2800

3300

3700

4200

4500
Series II

$\mathrm{U} g / 1$ in Effluent

0.23 .

0.59

0.74

0.84

0.86

There was a twenty-four hour lag between Series I and Series II raffinate flow which appeared to increase the uranium capacity of the wax slightly. The capacities for this run are as follows:

Capacity to $12 \%$ leakage $=20 \mathrm{mg} \mathrm{U} / \mathrm{g}$ wax

Capacity to $78 \%$ leakage $=43 \mathrm{mg} \mathrm{U} / \mathrm{g}$ wax 
No further work using a column has been done in the laboratory, however, pilot plant work has been started along this line.

II. Batchwise Process

Since it would be desirable to be able to handle raffinate without filtration, it was decided to work on a process which could be used with slurries. A batchwise contact was tried previously (NYO 1352 and NYO 1354) without too much success. However, with agitation such that the agitator does not come in direct contact with the wax, satisfactory operation has been obtained. Also a modification in the wax composition produced a product which tends to ball slightly rather than break down.

In the first batchwise experiment raffinate slurry was contacted with $30 \%$ TBP in wax. Results are given In Table II.

\section{Table II}

\section{Extraction of Uranium from Raffinate Slurry Using 30\% TBP in Wax}

Conditions:

$550 \mathrm{~g}$ wax used (dry basis)

Wax composition (weight basis)

30\% Tributyl phosphate

27\% Glyco Acrawax C

43\% Glyco S-1167 wax

Nine liters raffinate each run

No regeneration between runs

Room temperature

\begin{tabular}{ccc}
$\begin{array}{c}\text { Time of Stirring } \\
\text { minutes }\end{array}$ & $\begin{array}{c}\text { Run I } \\
\mathbf{U} \text { g/I }\end{array}$ & $\begin{array}{c}\text { Run II } \\
\mathbf{U} \text { g/ }\end{array}$ \\
\hline 0 & $\frac{1.75}{2.20}$ \\
15 & 0.31 & 0.86 \\
30 & 0.24 & 0.62 \\
45 & 0.22 & 0.77 \\
60 & 0.16 & 0.56 \\
90 & 0.03 & 0.50
\end{tabular}


The capacity of the wax for these two runs was $28 \mathrm{mg} \mathrm{U} / \mathrm{g}$ wax at the end of the first run, and $56 \mathrm{mg} \mathrm{U/g}$ wax at the end of the second run. These results were some what encouraging, but the wax was apparently too brittle and had a tendency to break down. Also a greater ratio of wax to volume of raffimate appeared to be needed to extract the uranium more quickly and completely.

Another composition of wax was then tried with better results, as are indicated in Table III.

\section{Table III}

Conditions:

$2200 \mathrm{~g}$ wax used (dry basis)

Wax composition (by weight)

50\% Tributyl phosphate

50\% Shell MX-170 wax

Nine liters raffinate each run

No regeneration of wax between runs

\begin{tabular}{|c|c|c|c|c|}
\hline $\begin{array}{l}\text { Time of } \\
\text { Stirring }\end{array}$ & $\begin{array}{l}\text { Run } \mathbf{I} \\
\mathbf{U} \mathbf{g} / \mathbf{1} \\
\end{array}$ & $\begin{array}{l}\text { Run II } \\
U_{B} / 1 \\
\end{array}$ & $\begin{array}{l}\text { Run III } \\
\text { U g/1 } \\
\end{array}$ & $\begin{array}{l}\text { Run IV } \\
\mathbf{U g} / \mathbf{1} \\
\end{array}$ \\
\hline 0 & 2.2 & 1.2 & 5.0 & 5.3 \\
\hline 15 & 0.10 & 0.17 & 0.14 & 1.3 \\
\hline 30 & 0.09 & 0.04 & 0.05 & 0.38 \\
\hline 60 & $0.009^{*}$ & & & 0.23 \\
\hline 90 & $0.006^{*}$ & & & 0.15 \\
\hline
\end{tabular}

- Fluorimetric analysis

During Run IV the wax was held in place using a stainless steel basket, 8 mesh, and largely explains the slower rate of uranium recovery during this run.

This particular wax composition behaved very well, actually rolling into distinct balls approximately $1 \mathrm{~mm}$ in diameter. No small praticles of wax were noted.

The capacity of the wax to the end of Run IV was $52 \mathrm{mg} \mathrm{U/g} \mathrm{wax.} \mathrm{How} \mathrm{much} \mathrm{higher} \mathrm{the} \mathrm{limit-}$ ing practical capacity is will have to be determined by future experiments. 
In this process using the above ratio of wax to raffinate, the uranium from at least four batches of raffinate could be recorered before regeneration of the wax would be necessary. If more than one stage of contact is used, the number of batches treated prior to regeneration would undoubtedly be greatly increased.

The wax used in the last experiment was washed with $1500 \mathrm{ml}$ of $2 \mathrm{M} \mathrm{Mg}\left(\mathrm{NO}_{3}\right)_{2}$ to remove most of the raffinate left on the wax particles. The uranium was then stripped from the wax using distilled water. The results are given in Table IV.

Table IV

Cocurrent Stripping of Uranium from Wax-TBP

Strip solution I $=5.5$ liters of distilled water Strip solution II $=9.0$ liters of distilled water

Total uranium on $\operatorname{wax}=115.3 \mathrm{~g}$

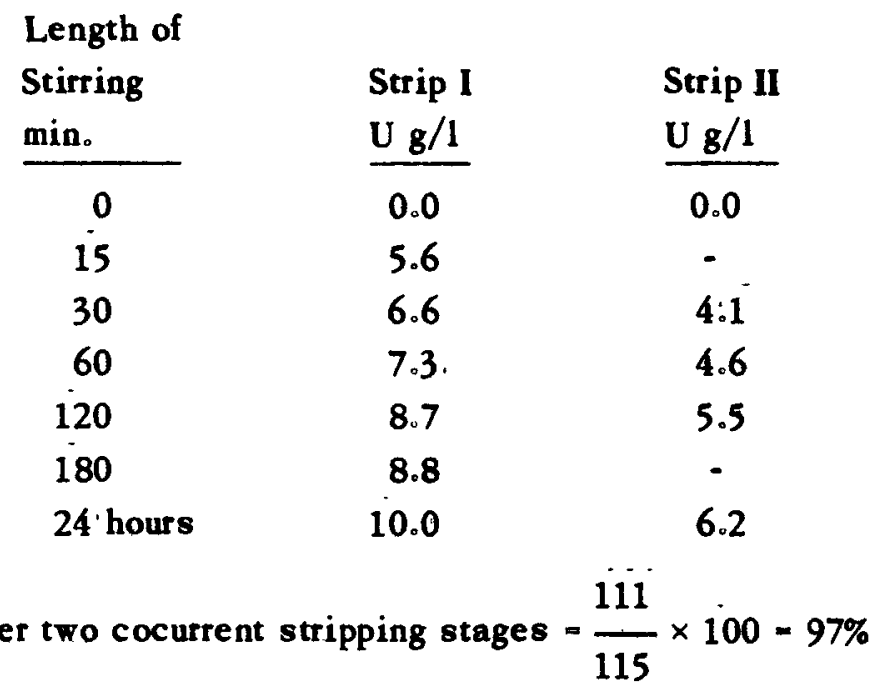

By using countercurrent stripping with several stages a higher concentration of uranium could be obtained. Pilot plant work is being planned to investigate this, and more fully evaluate the whole process.

III. Equilibrium Data

Some data on the equilibrium between TBP-wax and uranyl nitrate solution has been obtained. Results are given in Table $V$. 


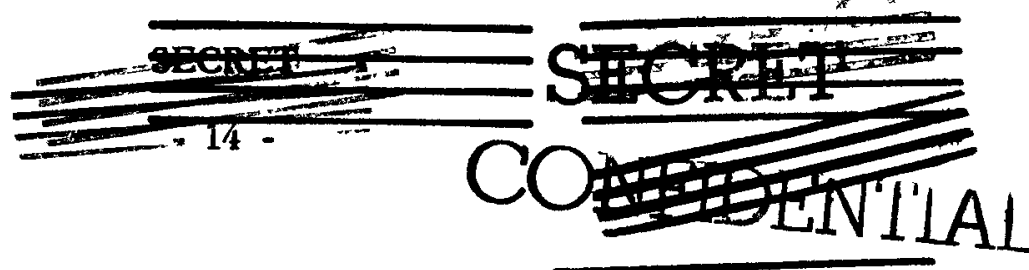

Table V

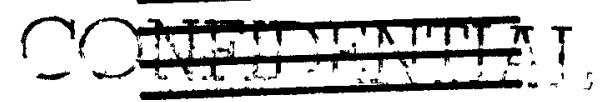

Equilibrium Data for TBP-Wax and Uranyl Nitrate Solution

Conditions:

$\mathrm{UO}_{2}\left(\mathrm{NO}_{3}\right)_{2} \cdot 6 \mathrm{H}_{2} \mathrm{O}$ used to make up solution

$200 \mathrm{ml}$ of solution

$20 \mathrm{~g}$ wax containing no uranium

Temperature $30.35^{\circ} \mathrm{C}$

Stirred 24 hours

Wax composition (by weight)

50\% TBP

$50 \%$ Shell MX-170 wax

\begin{tabular}{|c|c|c|c|}
\hline Run & $\begin{array}{l}\text { Conc. } \mathrm{U} \\
\text { in Wax } \\
\mathrm{mg} \mathrm{U} / \mathrm{g} \text { Wax }\end{array}$ & $\begin{array}{l}\text { Conc.U } \\
\text { In Solution } \\
\text { mg U/g sol }\end{array}$ & $K_{d}=\frac{m g \text { U/g } \max }{m g ~ U / g ~ s o l}$ \\
\hline$i$ & 62 & 45 & 1.38 \\
\hline 2 & 11 & 19 & 0.58 \\
\hline 3. & 6.9 & 9.6 & 0.72 \\
\hline 4 & 3.4 & $4: 9$ & 0.69 \\
\hline 5 & 0.7 & 0.96 & 0.73 \\
\hline 6 & 77 & 42.0 & 1.83 \\
\hline 7 & 47 & 37 & 1.27 \\
\hline 8 & 41 & 33 & 1.24 \\
\hline 9 & 30 & 28 & 1.07 \\
\hline 10 & 19 & 23 & 0.83 \\
\hline
\end{tabular}

The results of Table $\mathbf{V}$ are given graphically in Figure $i$, as well as the operating curve for determining countercurrent stages of stripping at a ratio of $1000 \mathrm{~g}$ solution to $250 \mathrm{~g}$ wax.

It may be seen that if the wax initially contains $100 \mathrm{mg} \mathrm{U} / \mathrm{g}$ wax, three countercurrent stages of stripping $w$ ill theoretically remove almost all the ufanium with stripping solution containing $25 \mathrm{~g} / \mathrm{l}$. Other waxes are to be tested to determine their influence on the distribution uranium between aqueous solutions and $\operatorname{wax}_{\text {. }}$

This equilibrium study is to be continued not only for TBP in waxes under different conditions, but also for evaluating new complexing agents and different waxes as they become arailable.

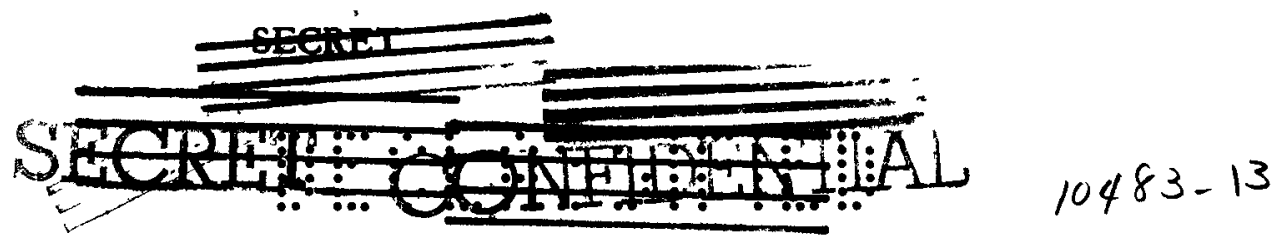




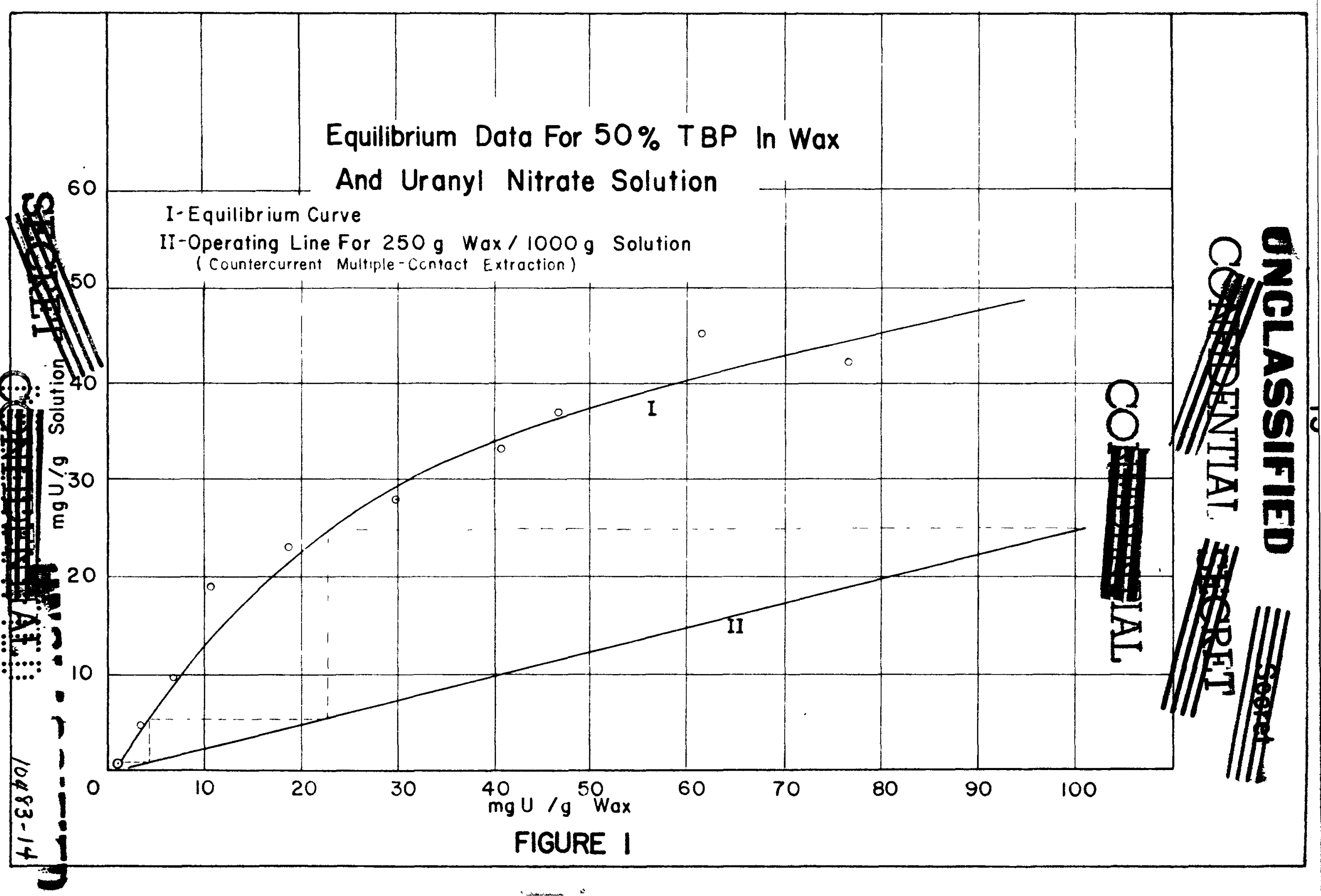


Coagulation of Silica through Boiling

A 50 gram sample of $21-2$ was calcined at $450^{\circ} \mathrm{C}$ for six hours and allowed to cool overnight in the pot furnace. Twenty-three $\mathrm{ml}$ of $71 \% \mathrm{HNO}$, and $70 \mathrm{ml}$ of water were added to the calcined material in a $250 \mathrm{ml}$ beaker. The beaker was set upon a hot plate and stirred with a stainless steel stirrer while the digest liquor was heated to boiling and maintained at boiling for one hour. The sample was removed from the hot plate; 25.0 grams of $\mathrm{Ca}\left(\mathrm{NO}_{3}\right)_{2} .4 \mathrm{H}_{2} \mathrm{O}_{2} 27.3$. grams of $\mathrm{Mg}\left(\mathrm{NO}_{3}\right)_{2} .6 \mathrm{H}_{2} \mathrm{O}$ and 20.0 grams $\mathrm{Al}\left(\mathrm{NO}_{3}\right)_{2} .9 \mathrm{H}_{2} \mathrm{O}$ were added and the volume adjusted to $90 \mathrm{ml}$. Then the $8 y 5 t e m$ was adjusted to $70 \mathrm{~g} \mathrm{HNO}$, per liter excess. Fifty $\mathrm{ml}$ of the adjusted liquor was shaken successively with four $-100 \mathrm{ml}$ volumes of neutral diethyl ether. The ether layers were added to $50 \mathrm{ml}$ of distilled water and evaporated. The samples were submitted to the analytical laboratory for analysis. The data are given in Table $I_{\text {}}$

\section{Table I}

\section{Extraction of Western Reef's Rand Material}

\begin{tabular}{|c|c|c|c|}
\hline Stage & Volume of Aqueous Layer & Uranium $\mathrm{g} / \mathrm{l}$ & Remarks \\
\hline Feed & 50 & 241 & in feed \\
\hline ist & 63 & $\ddot{118}$ & in ether layer* \\
\hline 2nd & 68 & 52 & $" \quad "$ \\
\hline 3 rd & 69 & 17.6 & " $"$ \\
\hline 4th & 68 & .71 & $" \quad "$ \\
\hline$\infty$ & $\infty$ & .52 & raffinate \\
\hline
\end{tabular}

* Analytical result for $50 \mathrm{ml}$ aqueous solution containing uranium originally present in $100 \mathrm{ml}$ ether.

These data indicate some emulsification occurred but extractions yielded a low uranium content raffinate。

Attempts were made to repeat this experiment using the pelleted Western Reefs material (21-3) . Heavy emulsions resulted during the first shake out. These results indicated that the conditions of calcining apparently have a marked influence upon the behavior of Rand Raw Material. The six hour calcining at $450^{\circ} \mathrm{C}$ apparently was sufficient for the powdered Western Reefs (21-2) material but not sufficient for the pelleted Western Reefs material.

Use of HF as Emulsion Inhibitor

Previous experience in this laboratory has indicated that digest slurries containing silicious sols may be occasionally treated with small amounts of HF to avoid emulsion formation during the
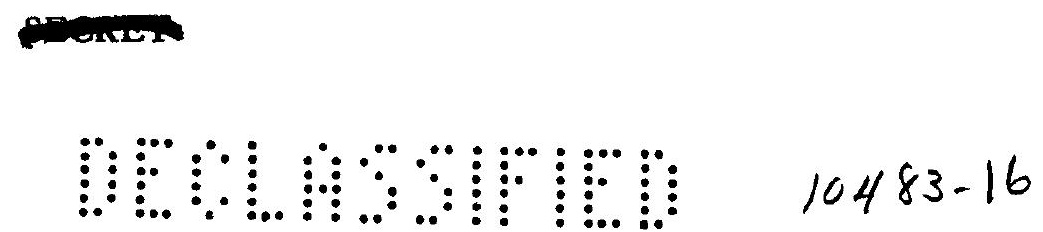


\section{SEenes}

ether extraction. Two experiments involving the treatment of digest liquors of pelleted Western Reefs (21-3) with HF were performed. In both experiments the conditions for calcining, digestion and extraction were like those described above. In Table II are the extraction data from a slutry to which was:added $1.0 \mathrm{ml}$ of $48 \% \mathrm{HF}$ before the addition of salting.agents. In Table III are the extraction data from a slurry to which was added $1.0 \mathrm{ml}$ of $48 \%$ HF with the salting agents already present; the addition of HF caused the instantaneous formation of a precipitate. Both extractions took place without emulsion formation.

\section{Table II}

HF Added Before Salting Agents

\begin{tabular}{|c|c|c|}
\hline Stage & Uranium $\mathrm{g} / \mathrm{l}$ & Remarks \\
\hline Feed & 211 & in feed \\
\hline ist & 129 & in ether layer* \\
\hline 2nd & 62 & $n n$ \\
\hline 3 rd & 22 & $n n$ \\
\hline 4th & 4.4 & " " \\
\hline$\cdots$ & 2.1 & raffinate \\
\hline
\end{tabular}

- Analytical result for $50 \mathrm{ml}$ aqueous solution containing the uranium originally present in $100 \mathrm{ml}$ ether layer.

Table III

HF Added After Salting Agents

\begin{tabular}{lcll} 
Stage & Uranium $8 / 1$ & & \multicolumn{2}{l}{ Remarks } \\
\cline { 2 - 3 } Feed & 188 & & in feed \\
18t & 104 & & in ether layer* \\
2nd & 32.8 & " & " \\
3rd & 14 & " & " \\
4th & 7 & " " " & " \\
& 21.6 & & raffinate
\end{tabular}

- Analytical result for $50 \mathrm{ml}$ aqueous solution containing the uranium originally present in $100 \mathrm{ml}$ ether layer. 
The addition of HF appears to condition the silicious sols to avoid emulsions during extraction. However, the concentrations of HF used here appear to seriously inhibit the extraction judging from the raffinate assays. It is possible that a lower amount of HF might avoid emulsification and still permit good extraction. This latter possibility will be investigated on more typical Rand Raw Material when such material becomes available.

\section{Conclusions}

Tentatively the results of the experiments described indicate that filtration does not aroid emulsification during the extraction step.

Coagulation of the silicious sols in certain digest slurties may be accomplished through boiling. The extraction of this coagulated material appears to be normal and raffinate uranium assays are low. However, coagulation through boiling does not appear to be very effective with improperly calcined material.

The use of HF aroided emulsions but appeared to inhibit the extraction of uranium. 
HIGH AMMONIUM OXALATE INSOLUBLE IN UF,

by

R. M. Paine

J A. Rode

\section{Introduction}

The problem of high $A_{\circ} O_{10} I_{0}$ in MCW UF 4 continues to be studied Current investigations are being directed toward the UO, from which $\mathrm{UF}_{4}$ is made. The reactivity studies of $\mathrm{UO}_{3}$ reported in NYO 1354, Pp27ff, are being continued and additional results are reported here. Some surface area measurements and tap densities are also reported. Preliminary X-ray diffraction data on $\mathrm{UO}_{3}$ are discussed briefly.

\section{Conclusions}

The results of this series of investigations ate inconclusive, but the work is being continued. Definite conclusions will be presented in a later report.

\section{Recent Reactivity Studies of $\mathrm{UO}_{3}$}

The results reported here were obtained from samples reduced and hydrofluorinated with the apparatus described in NYO 1354, $\mathrm{pp} 27 \mathrm{ff}_{8}$ and using an identical procedure. The existing equipment, however, is now being modified in an attempt to provide more consistent results from run to run. The modifications now in progress include the addition of an HF flowmeter and changes in the inlet and outlet gas connections to the furnace in order to provide a more even flow of gas over the twelve samples.

Data obtained from some of the recent runs are shown in Table 1 . Previous results had indicated that heating the $\mathrm{UO}_{3}$ caused the $\mathrm{A} . \mathrm{O} . \mathrm{I}$. to increase, and this effect was substantiated by Runs A15 through $\mathrm{A18}$. The temperature to which the $\mathrm{UO}_{3}$ was heated appeared to be more important than the length of time of heating. Runs A17 and A18 were made with samples withdrawn from two different pots at various times after the batch was done* All samples in each run were taken from the same batch. Although the effect of the additional heating time after done was to increase the $A .0 . I$. of the green salt produced, differences greater than those produced by additional heating wete noticed, in these and in subsequent runs, between various batches of UO,

* In this report the term done refers to that point at which the powder becomes dry. At this point burners are shut off. Cooling is a slow process, however, and the oxide is still fairly hot two hours later at which time the pot is unloaded. 


\section{Table I}

Results of the Reduction and Hydrofluorination of Various Samples of $\mathrm{UO}_{3}$

g HF

Run Used

A15

A16

258

A17

401

A18

460

\section{Sample}

Batch 222, Pot 10 , as is

0.12

Batch 222, Pot 10 , heated $250^{\circ} \mathrm{C}, 1 \mathrm{hr}$.

0.20

Batch 222, Pot 10 , heated $350^{\circ} \mathrm{C}, 1 \mathrm{hr}$.

Batch 222, Pot 10 , heated $450^{\circ} \mathrm{C}, 1 \mathrm{hr}$.

0.14

0.14

Batch 222, Pot 10, heated $600^{\circ} \mathrm{C}, 1 \mathrm{hr}$.

0.46

Batch 222 , Pot 10 , heated $750^{\circ} \mathrm{C}, 1 \mathrm{hr}$.

0.82

0.18

Batch 222, Pot 10 , as is

0.34

Batch 222, Pot 10 , heated $250^{\circ} \mathrm{C}, 1 \mathrm{hr}$.

Batch 222 , Pot 10 , heated $250^{\circ} \mathrm{C}, 2 \mathrm{ht}$.

0.41

0.44

Batch 222 , Pot 10 , heated $350^{\circ} \mathrm{C}, 1 \mathrm{hr}$.

0.37

0.22

Batch 222, Pot 10 , heated $350^{\circ} \mathrm{C}, 3 \mathrm{hr}$.

0.16

0.45

0.70

0.73

0.91

1.00

Sample $60 \mathrm{~min}$. after done

Obtained

from Fast Pot

0.02

0.12

0.07

Obtained

from Slow Pot

0.41

0.15

0.33

Sample $120 \mathrm{~min}$. after done

\section{Continued}


Table I (cont $\left.{ }^{i} d_{0}\right)$

g HF

Run Used

Sample

\% A.0.1. in UF 4

A25 $\quad 397$

Standard $\mathrm{UO}_{3}$

Continuous $\mathrm{U}_{3} \mathrm{O}_{8}{ }^{3}$, on 60 mesh fraction

Continuous $\mathrm{U}_{3} \mathrm{O}_{3}$ on 200 mesh fraction

Continuous $\mathrm{U}_{3} \mathrm{O}_{3}$ on 325 mesh fraction

2.40

Continuous $\mathrm{U}_{3} \mathrm{O}_{8}$, through 325 mesh fraction

1.02

${ }^{3}$ All samples, except where stated otherwise, were first screened through a 30 mesh sieve to remove the very large particles.

${ }^{2}$ One lot of $\mathrm{UO}_{3}$ was arbitrarily chosen as a standard. This lot was from normal plant production in August, 1952, when A.O.I. analyses were averaging about $1 \%$ 。

shis was recently produced in the Pilot Plant Continuous Denitration Furnace.

all sampled at approximately the same time after done. Fluctuations in the $A_{0} O_{0} I_{0}$ of the resulting $\mathrm{UF}_{4}$ were noticed in samples taken from various pots immediately after done。

Comparison of the A.O.1. ${ }^{\circ}$ s between Runs A17 and A18 indicated in general that the two oxides differed considerably at the time the first sample was withdrawn, $i_{\circ} e_{\circ}$, immediately after done.

The original sample used in Runs A15 and A16 was taken from a slow pot 10 minutes after done. This sample gave a fairly low A.O.I. except when heated to a very high temperature before the reactivity test. A sample taken from a very fast pot 5 minutes after done and treated as in $R$ un A15 gave A.O.1.'s ranging from $1.0 \%$ to $4: 2 \%$ (Run A13, NYO 1354; $\mathrm{p} 32$ ) depending upon the temperature to which it was heated.

The results of Run $A 25$ indicated that $\mathrm{U}_{3} \mathrm{O}_{3}$ produced in early experiments by the continuous process is not very reactive even when ground to a very fine powder. The decomposition cycle in the production of continuous $\mathrm{U}_{3} \mathrm{O}_{3}$ and $\mathrm{UO}_{3}$ may not have been favorable to the production of a reactive product.

- Pots which have relatively short heating cycles are generally referred to as fast pots, while those with long heating cycles are referred to as slow pots. 
Additional samples taken from plant pots indicated that the $\mathrm{UO}_{3}$ which produced the $\mathrm{UF}_{4}$ with high A.O.I. generally came from fast pots, while only occasionally did a slow pot produce UO, which gave high A.O.I. UF, However, the fast pots also produced good $\mathrm{UO}_{3}$ much of the time. The samples used in these runs were obtained from regular plant production batches. Some difficulty was encountered in making accurate correlations between the heating cycle of a particular batch and the $\mathrm{A}_{0} \mathrm{O}_{1} \mathrm{I}_{\mathrm{o}}$ of the resulting $\mathrm{UF}_{4}$ for several teasons. The pot cycles varied orer a wide range and it was sometimes difficult to say that a pot was either fast or slow.

In many instances when a pot was running slow, one or more extra burners were turned on for the remainder of the cycle. This caused overheating of the final $\mathrm{UO}_{3}$ and could possibly have offset any advantages of a slow cycle. To complicate matters still further, it is difficult for the pot . room operators to keep records of the accuracy required for a controlled experiment.

In view of these circumstances the decision was made to run closely controlled experiments in the plant. For this purpose permission was obtained to use two plant pots for research purposes during the day shift. An experienced operator was also provided to give full time attention to these two pots

Although the processing of these plant samples is as yet incomplete, several rather interesting observations have been made. Preliminary tests indicated that the orange oxide cake formed on the pot walls (mill cake) produced high $A_{0} O_{0} I_{\text {. UF }}{ }^{\circ}$ Since the oxide appeared to cake extensively on cool pot surfaces, $i_{\circ} e_{\circ}$, those surfaces which did not get the direct heat of the gas flame, uniform heating on the pot surfaces from light dough stage* to done might improve the product noticeably. The elimination of caking problems would simplify unloading of the pots. Experiments indicated that uniform, low-temperature heating of the pot from dough to done does indeed reduce the magnitude of the caking problem $_{8}$ though the plough clearance is undoubtedly a major factor influencing the caking tendency. Further work along these lines is in progress 。

Several runs were made in which the oxide powder was heated for 30 minutes after done. No serious change in the appearance of the product resulted. Some black oxide apparently did form on the outer surface of the $\mathrm{UO}_{3}$ cake, but no change in the luster of the powder was observed**.

- Light dough stage is that stage at which bubbling liquid can no longer be observed in the pot.

** The presence of $\mathrm{U}_{3} \mathrm{O}_{8}$ in the $\mathrm{UO}_{3}$ generally reduces the luster of the powder; sometimes to such an extent that the product is hardly recognizable as orange oxide. 
$\mathrm{X}$-ray Diffraction Studies of $\mathrm{UO}_{3}$

Preliminary studies of $\mathrm{UO}_{3}$ and its hydrates using the Norelco Diffractometer agreed quite well with the work done at Battelle ${ }^{1}$ where the usual film technique had been used. However, there has as yet been no comparison of actual patterns between MCW and Battelle. In the future it is hoped that the various phases will be fully characterized, and definite patterns established for each phase. At the moment, concern is centered about differences in phases, and how these differences might affect reactivity.

A recent sample of good MCW UO, (Batch 330), Hanford Lot HL06i, and a sample of continuously produced UO, all gave the same $\mathrm{X}$-ray pattern, although the Hanford and the continuous $\mathrm{UO}_{3}$ also gave a weak hydrate pattern (arbitrarily called Hydrate I) 。

The Hanford $\mathrm{UO}_{3}$ and the continuous $\mathrm{UO}_{3}$ were hydrated by slurrying hot for one hour and drying at $110^{\circ} \mathrm{C}$ overnight. The hydrated Hanford oxide gave a very clear pattern, indicative of good crystal growth. This pattern was designated as Hydrate $I$ and is presumed to correspond to Battelle ${ }^{\circ}$ type " $A$ " hydrate The continuous $\mathrm{UO}_{3}$ gave the Hydrate I pattern plus an additional hydrate pattern (designated Hydrate II); the two hydrates were estimated to be in a $\dot{1}: \dot{1}$ ratio. The continuous $\mathrm{UO}_{3}$ hydrate also contained a small amount of the original anhydrous phase, indicating that hydration of continuous $\mathrm{UO}_{3}$ was more difficult than hydration of Hanford $\mathrm{UO}_{3}$ 。

The Hanford $\mathrm{UO}_{3}$ hydrate and the continuous $\mathrm{UO}_{3}$ hydrates were then heated at $350^{\circ} \mathrm{C}$ for an extended period (more than 20 hours), both giving a very dark orange product. The X-ray patterns obtained with both of these materials consisted of only a few short ${ }_{2}$ broad lines. The major portion of both samples was either composed of extremely small crystals or amorphous material. That fraction of Hanford oxide which did give an identifiable pattern was the original anhydrous. $\mathrm{UO}_{3}$ phase, while the crystalline fraction which was converted from the hydrated continuous $\mathrm{UO}_{3}$ was mainly an entirely new phase containing only a very small amount of the original anhydrous phase.

Data was presented in NYO 1354 (p33) which indicated that hydration (or hydration with subsequent heating) of Hanford oxide greatly improved the reactivity, while similar treatment of the continuously produced oxide did not affect the reactivity.

\section{Surface Area of $\mathrm{UO}_{3}$ vs Reactivity}

Some surface area measurements of $\mathrm{UO}_{3}$ were made by $\mathrm{J}$. W. Stevenson using a methane adsorption

\footnotetext{
${ }^{2}$ Private communication from Dr。 Co M. Schwartz.
} 
procedure at liquid nitrogen temperatures. Surface areas from 0.7 to 1.8 square meters/gram were obtained, but they indicated no correlation with $A_{0} O_{0} I_{10}$ of the resultant $U_{4}$. The $A_{0} O_{0} I_{0}{ }^{3} s$ decreased with increasing surface area in some instances, but the reverse was also noticed.

The hydrated $\mathrm{UO}_{3}$ and the hydrated $\mathrm{UO}_{3}$ which had been reconverted to anhydrous oxide by heating had only average surface areas.

Some Tap Densities of $\mathrm{UO}_{3}$ and $\mathrm{UO}_{3}$ Hydrate

The improved reactivity of $\mathrm{UO}_{3}$ resulting from hydration stimulated interest in the effect of hydration on tap density. Results shown below are typical of oxides and their hydrates as prepared in this laboratory. Preparation of hydrates with higher densities may be possible, and work along this line is anticipated.

\section{Sample}

MCW UO,

MCW UO, hydrated (monohydrate)

$\mathrm{MCW} \mathrm{UO}_{3}$ hydrate reconverted to anhydrous

Continuously produced $\mathrm{UO}_{3}$

Cont. UO, hydrated (monohydrate)

Cont $\mathrm{UO}_{3}$ hydrate reconverted to anhydrous
Tap Density, g/cc

4.2

2.5

2.6

4:1

2.7

2.9 


\section{THE RECOVERY OF HF AND URANIUM FROM MgF 2 BOMB SLAG}

by

J. W. Stevenson

Introduction

This work concerns the recovery of uranium and $\mathrm{HF}$ from bomb slag, $\mathrm{MgF}_{2}$. Previous reports on this problem were presented in NYO 1349, NYO 1352, and NYO 1354.

$\operatorname{Aim}$

The aims of this study continue to be:

1 To establish a process that will reduce the uranium content of slag to less than $0.05 \%$ and at the same time permit recovery of most of the fluoride.

2. To investigate various processes in order to gain as much economy and flexibility in slag handling as possible.

\section{Summary}

Slag is definitely not as reactive as fluorspar toward sulfuric acid. It appears that only a plant test will establish the magnitude of this difficulty.

Sodium carbonate leaching and washing of very finely ground slag does not consistently remove uranium to less than $0.05 \%$ in the treated slag. Because of the potential advantages of this process it may be reconsidered from time to time but at present no further work is planned.

Even dilute acid, $1 \%$, dissolves appreciable amounts of slag. This is objectionable because it leads to fluoride contamination of the uranium concentrate. It has not been established that an excess of $1 \%$ acid will result in satisfactory uranium removal although it is known that $10 \%$ acid is satisfactory. Because a dilute $\mathrm{H}_{2} \mathrm{SO}_{4}$ leach process seems to offer the best method of uranium recovery, future work will be directed toward gathering pre-pilot plant data for this process.

\section{Experimental Data and Discussion}

Most of the effort on these problems, during the past quarter, has been directed toward examining literature and experimental data in order to narrow the field of study to one or possibly two of the most promising methods. The limited amount of experimental work which has been done has served to solidify the conclusions which evolved from this consideration of past work. 
Two additional samples of fluotspar were tested by reacting with $\mathrm{H}_{2} \mathrm{SO}_{4}$ in platinum at $190^{\circ}$ to $215^{\circ} \mathrm{C}$. The percent reacted versus time of reaction is shown in Table $\mathrm{I}$.

\section{Table I}

Reaction of Fluorspar with $\mathrm{H}_{2} \mathrm{SO}_{4}$ (B120P108)

\begin{tabular}{|c|c|c|}
\hline \multirow{2}{*}{$\begin{array}{l}\text { Time } \\
(\min .)\end{array}$} & \multicolumn{2}{|c|}{$\%$ Reacted } \\
\hline & Sample I & Sample II \\
\hline 10 & 59 & 52 \\
\hline 20 & 69 & 61 \\
\hline 30 & 75 & 65 \\
\hline 40 & 77 & 69 \\
\hline 50 & 80 & 71 \\
\hline 60 & 86 & 73 \\
\hline 70 & 91 & 74 \\
\hline
\end{tabular}

Screen analyses for these samples are giren in Table II (Bi14P32).

Table II

Screen Analyses of Fluorspar Samples

Screen Size

$\begin{array}{lrrrr}\text { Sample } & \frac{+200}{\text { I }} & \frac{-200+325}{-7.8 \%} & \frac{-325}{38.9 \%} & \frac{53.4 \%}{\text { II }} \\ 31.0 \% & & 40.0 \% & 26.8 \%\end{array}$

When compared with previous work, this experiment confirms the belief that fluorspar is much more reactive toward $\mathrm{H}_{2} \mathrm{SO}_{4}$ than is slag. It appears that only a plant scale test of slag will provide the quantitative data required to judge the seriousness of this difference in reactivity.

At Prof. Shreve's suggestion a sample of slag was heated to $700^{\circ} \mathrm{C}$ then water quenched. The thought was that such a procedure might make the slag more reactive toward $\mathrm{H}_{2} \mathrm{SO}_{4}$. However, the slag still appeared to be quite coarse. When reacted with a two-fold excess of $\mathrm{H}_{2} \mathrm{SO}_{4}$ at 200 to $250^{\circ} \mathrm{C}$ for 1 hour, $48 \%$ of the slag reacted compared to $45 \%$ reaction for untreated slag (B131P26). 


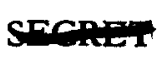

The screen analysis of this slag before treatment is given in Table III (B120P113)。

Table III

Screen Analysis of Slag

$\begin{array}{lc}\frac{\%}{\text { Screen }} & \frac{\%}{100} \\ -100+200 & 23.1 \\ -200+325 & 22.8 \\ -325 & 14.0 \\ & 40.1\end{array}$

This experiment showed that the heating and quenching did not improve the reactivity of the slag.

An experiment involving hot ball milling of a slag $\star \mathrm{Na}_{2} \mathrm{CO}_{3}$ slurry was mentioned briefly in last quarter's report as offering promise. This experiment will be described, not because it was successful, but because it was almost successful and because a carbonate process would have a number of advantages.

Four hundred fifty four grams of slag was milled in a 1 gallon porcelain jar closed with a brass lid bearing a pressure relief device. One quart of flint pebbles was used. The mill also contained

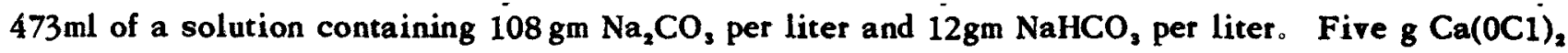
was added as an oxidant. The temperature was maintained at 70 to $80^{\circ} \mathrm{C}$ a As each sample was taken it was filtered and slurry washed with water for $1 / 2$ hour at $80-90^{\circ} \mathrm{C}$.

As will be shown below the uranium was still undersirably high in the residue. Therefore, the samples were reslurried for $i$ hour at $80-90^{\circ} \mathrm{C}$ in a dilute $\mathrm{Na}_{2} \mathrm{CO}_{3}$ liquor at $3 . \mathrm{lbs}$. dry solids/gal. The $\mathrm{Na}_{2} \mathrm{CO}_{3}$ liquor contained $27 \mathrm{~g} \mathrm{Na} \mathrm{NO}_{3}$ and $3 \mathrm{~g} \mathrm{NaHCO}$ per liter. This filtrate gave a qualitative test for uranium, therefore, the cake was washed twice more with dilute carbonate liquor. The final filtrate did not give a qualitative test for uranium. Two different samples of slag were tested. The results appear in Table $\mathbf{I V}$.

Table IV

Hot Carbonate-Slurry Milling of Slag

\begin{tabular}{|c|c|c|c|c|}
\hline Sample & $\begin{array}{l}\text { Initial } \\
\% \mathrm{U}\end{array}$ & $\begin{array}{l}\% \mathrm{U} \text { after } \\
6 \text { hours }\end{array}$ & $\begin{array}{l}\% \mathrm{U} \text { after } \\
12 \text { hours }\end{array}$ & $\begin{array}{l}\% \mathrm{U} \text { after } 12 \text { hours } \\
\text { and } 3 \text {, dilute } \mathrm{Na}, \mathrm{CO} \text {, washes }\end{array}$ \\
\hline $\begin{array}{l}1 \\
2 \\
\text { Two }\end{array}$ & $\begin{array}{l}\overline{1.13} \\
1.60 \\
C 0\end{array}$ & $\begin{array}{c}0.13 \\
0.20 \\
\text { B114P33 }\end{array}$ & $\begin{array}{l}0.15 \\
0.11 *\end{array}$ & $\begin{array}{l}0.05 \\
0.09\end{array}$ \\
\hline
\end{tabular}


In another series of experiments much the same sort of test was made except that the slags were ground to -325 mesh to start with and the digestion was in beakers rather than the mill. The slurries were more dilute but the carbonate concentration was unchanged. The digestions were made at 90 to $100^{\circ} \mathrm{C}$ and $\mathrm{H}_{2} \mathrm{O}_{2}$ was maintained in excess. Digestion and washing were continued until the final digest filtrate did not give a qualitative test for uranium (Bi3iPi6). The results are given in Table $\mathbf{V}$.

\section{Table V}

Residual Uranium In Carbonate Leached Slag

\begin{tabular}{cc} 
Sample & $\frac{\% U}{1}$ \\
\hline 1 & 0.07 \\
3 & 0.05 \\
\hline & 0.08
\end{tabular}

Taken together these two sets of experiments show that the carbonate leaching process at the present stage of development will not satisfactorily remove uranium from slag. Therefore, no further work on this process is planned. However, because of the potential advantages of a carbonate leach process, some work will be done from time to time as new approaches are suggested.

A brief experiment was performed to determine the solubility of slag in dilute acid and dilute carbonate. Ten grams of slag was heated for $i$ hour at 90 to $100^{\circ} \mathrm{C}$ with $100 \mathrm{ml}$ of solution. The slurries were filtered and the residues dried at $110^{\circ} \mathrm{C}$ and weighed. The data are shown in Table VI (B13íp23)。

\section{Table VI}

Solubility of Slag in Dilute Acids and Dilute Carbonate

\begin{tabular}{lc} 
Solution & \% Dissolred \\
\cline { 2 - 2 } Water & 0.0 \\
$1 \% \mathrm{H}_{2} \mathrm{SO}_{4}$ & 6.8 \\
$2 \% \mathrm{H}_{3} \mathrm{SO}_{4}$ & 8.1 \\
$1 \% \mathrm{Na}_{2} \mathrm{CO}_{3}$ & 0.5
\end{tabular}




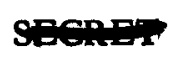

The screen analysis of this slag has been given in Table III. The initial uranium content was $0.51 \%$. Qualitative tests indicated that detectable amounts of uranium remained in the slag which is not surprising in view of the relative coarseness of the slag. The sample contained some constituent that was readily soluble in hot dilute acid as determined by titration of a slurry to methyl red end point. The amount of this constituent, calculated as $\mathrm{MgO}_{\text {, was }} \dot{1}_{0} 6 \%$. The amount of magnesium was not determined but was almost certainly less than $2.0 \%$. This experiment provides further evidence that some slag does dissolve in acid as dilute as $1 \% \mathrm{H}_{2} \mathrm{SO}_{4}$. The amount dissolved is approximately that which can be calculated from solubility products and ionization constants. This solubility of slag means that fluoride complexers and a final high temperature roast will be necessary to reduce the fluoride contamination of the uranium concentrate. Future work will be directed toward accumulating pre-pilot plant data for a dilute $\mathrm{H}_{2} \mathrm{SO}_{4}$ process 


\title{
METALLOGRAPHIC PROGRESS REPORT FOR THE SECOND QUARTER OF 1953
}

\author{
by
}

H. C. Kloepper, Jr.

O. L. Lisot

R. M. Paine

A. E. Ruehle

R. S. Vogel

\section{Introduction}

This program concerns the examination of uranium metal with respect to metal quality. Previous work is reported in NYO 1352 and NYO 1354.

\section{$\operatorname{Aim}$}

The aim of this program has been to seek out and identify the various types of inclusions found in the metal. We have also tried to help evaluate the development work of others in the light of the materials that have been identified and thereby hope to aid in their elimination from the product.

\section{Summary of Conclusions}

1. Superheating of the melt has very little effect on slag removal as determined in the cast ingot.

2. All mold design factors have not been evaluated but larger diameter molds are indicated as being better.

3. Egg cups painted with mold wash are slightly better than unpainted cups as far as ingot quality is concerned.

4. All "good crop" ingots are of very poor quality.

5. Some progress is being made in developing new techniques that can be applied to the identification of inclusions in uranium metal.

\section{Discussion of Results}

1. Examination of Pilot Plant Ingots

a. Heats 202 and 203 .

The purpose of this experiment was to see if a high holding temperature would volatilize more slag and produce a cleaner ingot. This idea was suggested by Mr. Kaulbach of the New York A.E.C. Office. The heats were cast in production type molds with 45" of zircon insulation, and having $0.1 \%$ slag added to the crucible charge. Heat 202 was held at $2550^{\circ} \mathrm{F}$ 
and poured while heat 203 was held at $2800^{\circ} \mathrm{F}$ and poured. Samples were taken 5", 25", and $40^{\prime \prime}$ from the bottom of each ingot.

A porosity examination of the samples from the two heats showed no difference in the number of slag inclusions.

b. Miscellaneous Mold Designs

The following pilot plant heats have been examined and have been ranked in the order of increasing porosity, the last heat being the most porous.

1. Heat 197 - $6 \%$ " diameter production mold, tapered insulation, top reflector.

2. Heat 196 - Self casting in crucible, cooled from $2200^{\circ} \mathrm{F}$ to $1800^{\circ} \mathrm{F}$ in 4 hours.

3. Heat 198 - 4\%" diameter production mold, tapered insulation, top reflector.

4. Heat 204 - Heat tapered step tapered type $A$ mold, tapered insulation, top reflector.

5. Heat 195 - Copper mold, water cooled, $1 / 4$ " pourhole.

As far as pin point porosity and inclusions is concerned they are all much better than regular production ingots. Heat 195, which is the most porous, is about 3 times less porous than a regular production ingot, and heat 197 is about 10 times less porous than a regular production ingot.

I1. Examination of Production Plant Ingots

a. Painted re Unpainted Cup Molds

$A$ series of ten ingote was cast in the production plant to determine the effect of painting the egg cups with a mold wash. Fire ingots were cast using painted cups and fire cast uning unpainted cups.

Samples from these ingots vere examined and counte made on the number of rolds, and the number of slag and oxide inclusions. The voide and slag were reduced by a factor of two in the painted mold but the oxide inclusions were increased by a factor of two, the orerall effect being reduction of about $2 / 2$ in the total pin point porosity and inclusion count.

Since it is postible to reuse an 888 cup mold that has been painted with a mold wash and the overall effect is a reduction in porcoity and inclusions this practice has been recommended for use in the production plant. 
b. All "Good Crop" Ingots

Five ingots were cast in which "good crop" made up the entire charge entering the melting crucible. The so-called "good crop" is the metal that is cropped from the top of the ingot after the top one inch or "top crop" is remored. "Good crop" is remored in one or two inch slices until density and pipe specifications are met.

Three of the five heats were examined in the laboratory and were found to be extremely porous and had a very large number of large slag and oxide. type imalusions. They also had numerous inclusions of a hard dark granular material that eppears to be sintered into a porous mass. Then subjected to X-ray diffraction using a technique to be described later, this material gave a diffuse $\mathrm{UO}_{2}$ pattern for its major constituent; other lines were obtained but have not yet been identified.

One of the larger shrinkage cracks was filled with a soft white material that was tinged with a reddish brown discolosation. An X-ray diffraction analysis of this material revealed its major constituent to be $\mathrm{MgO}$ and one of ita minor constituents has been identified as $\mathrm{UO}_{k}$. A typical photomicrograph of the all "good crop" material is shown in Figure 1.

The sintered dark granular material was prepared for X-ray diffraction by uaing a seplicatransfer technique. The sample was prepared for visual examination in the normal manner, then a lucite replica of the surface was made using a mounting press. The replica was broken away from the specimen revealing a plastic replica of the surface with some materials from the inclusions embedded in its surface, but projecting in relief. The plastic was sectioned in such a manner that it could be mounted in an Xray diffraction powder camera. Figure 2 is a reproduction of the pattern obtained. This technique is in the early stages of its development here at Mallinckrodt and is included because of its. novelty.

In the case of the $\mathrm{MgO}$ inclusion a plastic replica was not made but the material was dislodged with a needle and mounted on the end of a fine glass fiber with Canada Balsam. The sample was then mounted in an $\mathrm{X}$-ray diffraction ponder camera. The pattern obtained using this technique is thow $n$ in Figure 3.

\section{Examination of Slugs}

At the present time the examination of slugs is in the stage of method development. The methods used to identify inclusions in ingot metal of necessity have to be revised since the amount of sample obtainable from an inclusion only a few microns wide is very limited, It 


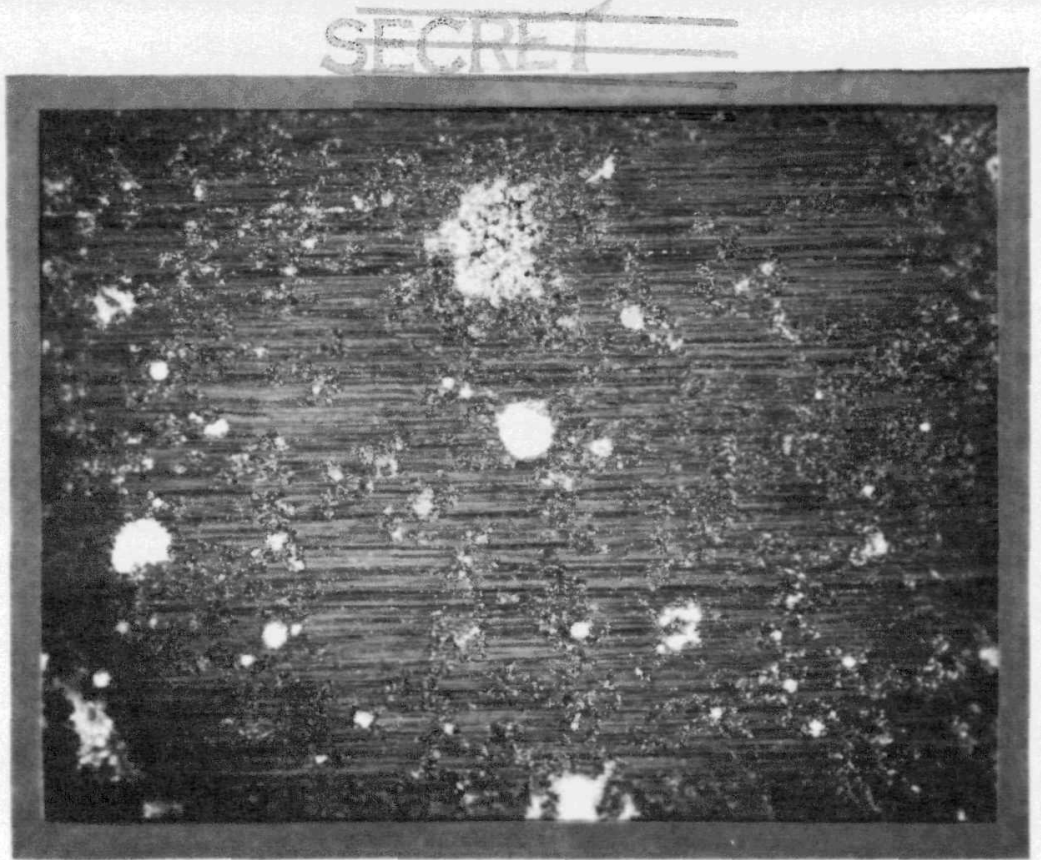

Figure 1.

A11 "good crop" heat Ho. 4663 howing numerous slag, oxide, and carbide inclusions. Sample

was rough ground on 400 SiC

paper and photographed at $50 \mathrm{X}$ under polarized $11 \mathrm{ght}$. 


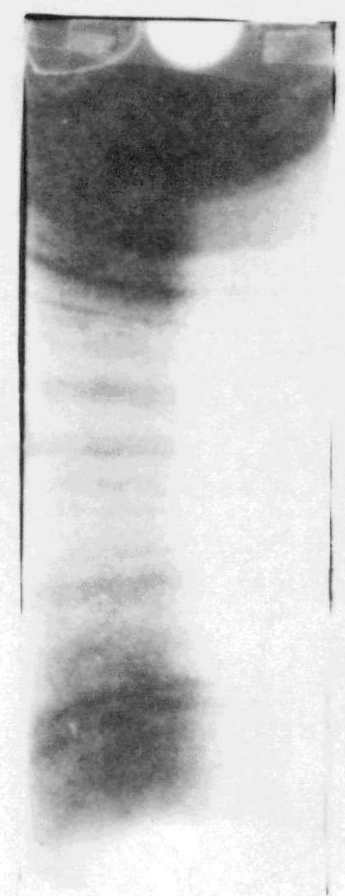

4.

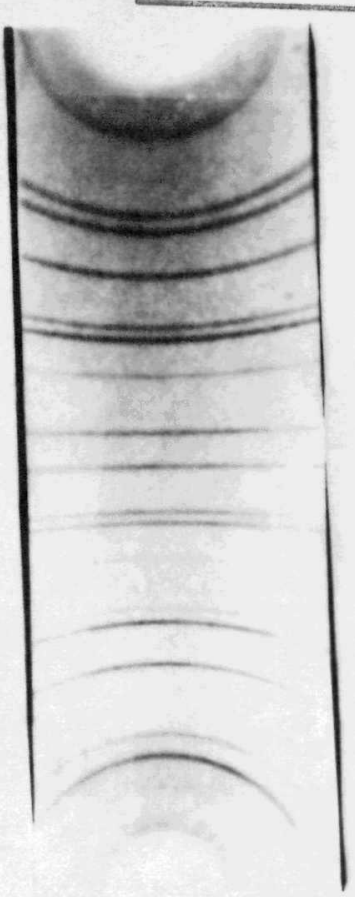

B.

\section{$\mathrm{Fg} \cdot 2$}

X-Ray diffraction patterns obtained with $57.3 \mathrm{mn}$ powder onera: A. Inolusion strippod out with Luoite. B. Standard $\mathrm{UO}_{2}$ pattern.

Fig.3

$X$-Ray diffraction pattorn obtained with $114.6 \mathrm{~mm}$ powder camera. Inolusion mounted on glase fibre.

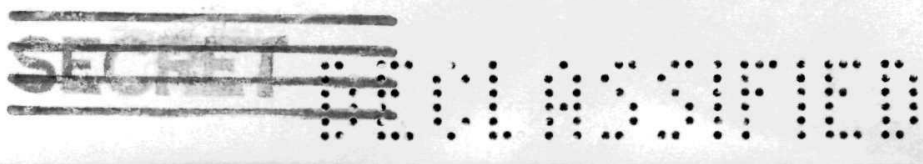


has forced us to work under higher magnification while trying to dislodge samples for spectrographic analysis. A rough calculation of the amount of material removed from a slag inclusion showed that we were able to transfer about 0.5 to 2.0 micrograms of material to a spectrographic electrode.

Samples of materials found in reject slugs have been analyzed by spectrographic means, and the analysis obtained on slag and oxide type inclusions are similar to those obtained on samples removed from ingots. It must be remembered that the small amount of impurities found in spectrographic graphite is of little or no concern when dealing with normal amounts of material, but becomes extremely important when handling samples in the limited amounts described above. In order to neutralize the effect of electrode impurities such techniques as preburning of electrodes, electrode blanks, etc., have been tried with some success.

In attempting to develop new transfer methods to be used in conjunction with X-ray diffraction and spectrographic techniques, it was noted that $1: 1 \mathrm{HCl}$ attacks the striations found in slugs at a faster rate than the surrounding metal. Therefore, some etching experiments were carried out. The acid after contacting the sample was analyzed spectrographically and was found to contain $\mathrm{U}, \mathrm{Si}_{2}$ and $\mathrm{Ca}$ over and above the blanks run on the materials involved. More work will have to be done before conclusions can be drawn. A micro spark technique for direct excitation of inclusions in metal is also under development.

In examining a number of reject slugs it was noted that slag does not conform in the rolling operation. A slag inclusion should be distorted longitudinally to 25 times its original diameter and transversely to $3 / 5$ of its original diameter. Figure 4 shows a slag inclusion in the midst of a number of striations. It is obvious that the slag has not been elongated 25 times. This fact alone ought to eliminate slag as a probable cause of striations in slugs. 


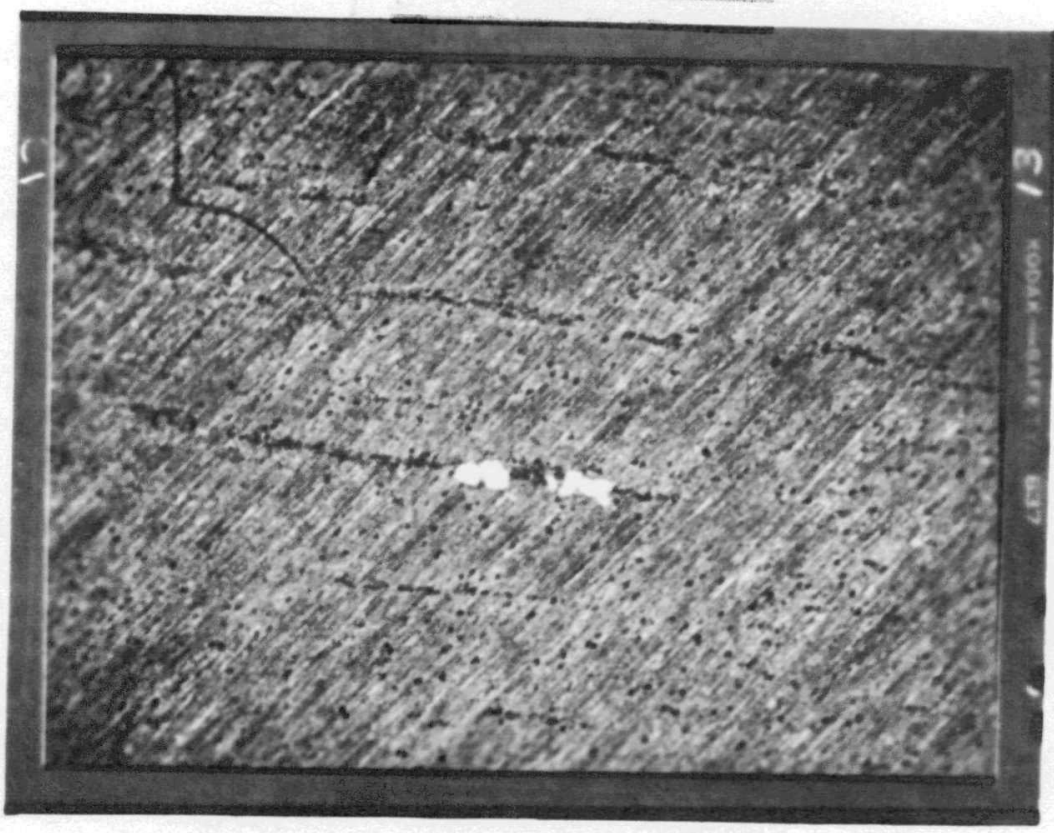

Pigure 4.

Reject lug rough ground on 400 grit SIC paper, photographed at $50 \mathrm{X}$ using polarized $11 \mathrm{ght}$. Rolling direction 1 in the direction of the striations and the hite slag materlal obviously does not conform in rolling operation. 


\section{CARBON CONTAMINATION IN CAST URANIUM}

by

R. D. Piper

\section{Introduction}

Work on decreasing the amount of carbon contamination incurred on melting uranium in graphite crucibles has been described in previous quarterly reports (NYO 1352 and NYO 1354). $\Lambda$ few additional tests have been made during this quarter and are described below.

\section{Experimental}

The apparatus and procedure previously described were used to test the effectiveness of an ethyl silicate bonded magnesia dressing. A slurry of powdered magnesia and ethyl silicate diluted with isopropyl alcohol was applied to the crucibles and partially hydrolyzed by using a crucible previously soaked in water or by storing the treated crucible in a moist atmosphere. $A$ soft, but fairly adherent coating. was produced by either method. On testing these coatings by melting uranium in the treated crucibles, ingots with $1000-1100$ ppm carbon were obtained, indicating only a slight improvement over untreated graphite and much poorer performance than the magnesia dressing now used in plant production which gives ingots with 500 ppm carbon $\sim$ under similar conditions.

Several $2 \frac{1}{4} \|^{n}$. diameter sintered magnesia crucibles have been receired from Norton Abrasive Co. and tested using five pound charges of derby metal. Two attempts to heat the metal directly by induction resulted in breaking the crucible, presumably from thermal strains set up on heating a piece of metal inside the crucible. One charge was melted successfully and heated to $2500^{\circ} \mathrm{F}$, using a steel sleeve outside the crucible as a susceptor for the induction heating. The resulting ingot met purity specifications and contained only $29 \mathrm{ppm}$ carbon. These tests, however, indicate that considerable care must be exercised in using this type of crucible to prevent thermal or mechanical breakage. 


\section{VACUUM FUSION OXYGEN. DETERMINATION}

by

R. D. Piper

\section{Introduction}

Increased emphasis on metal quality and on the use of crucible dressings or oxide crucibles have made it necessary to study oxygen contamination more closely than has been done heretofore. The best method available for determining oxygen in uranium is the racuum fusion method in which the uranium is melted under vacuum in an iron bath with an excess of carbon. At temperatures above $1750^{\circ} \mathrm{C}$ any oxygen or oxides present form carbon monoxide which is pumped off and analyzed. Nitrogen and hydrogen are also removed and can be determined from the same sample. Considerable work has been done on developing this method, and a few references are listed below. $2,2,3,4$

\section{Apparatus}

The apparatus used in this work was originally copied from a similar apparatus at Battelle Memorial Institute, but has undergone considerable modification. A photograph of the completed apparatus is shown in Figure 1 , and a schematic diagram of the system is shown in Figure 2.

The reaction takes place in a $1 \%{ }^{\prime \prime}$ O.D. $\times 3 "$ long graphite crucible which is mounted in a $1 \frac{1}{2} "$ I.D. quartz tube and insulated by loose graphite powder in the annular space. This assembly is contained in a 2" I.D. vacuum tight quartz tube and is supported in the induction coil by another quartz tube which rests on the bottom of the outer container. The outer quartz tube is sealed with Apiezon " $"$ " wax to a brass flange which is connected, by means of a flanged $I \frac{1}{2}$ " tube sealed with rubber "O" rings, to a Leybold's Nachfolger Hg45 mercury vapor diffusion pump. This pump has a pumping speed of $451 /$ second and provides rapid removal of evolved gases to minimize reabsorption of the gases by metal films formed on the walls of the appasarus.

A sample "tree" is mounted above the connection to the diffusion pump so that samples may be dropped, $_{2}$.without opening the system, by means of iron "pushers" operated by a magnet, $\Lambda$ glass sleeve, also mounted in the sample tree, can be moved in front of the sight glass on top of the tree to prevent the sight glass from becoming clouded with vapors from the crucible. Temperatures are measured through this sight glass using an optical pyrometer.

The crucible is heated using a $2 \%^{*}$ induction coil mounted outside the quartz tube. Power is supplied by a 10 kilocycle, $15 \mathrm{KW}$ Tocco motor generator set. The maximum outgassing temperature of $2200^{\circ} \mathrm{C}$ can be reached using only $20 \%$ of the rated output of the unit. 
Figure 1

Vacuum Fusion Apparatus 


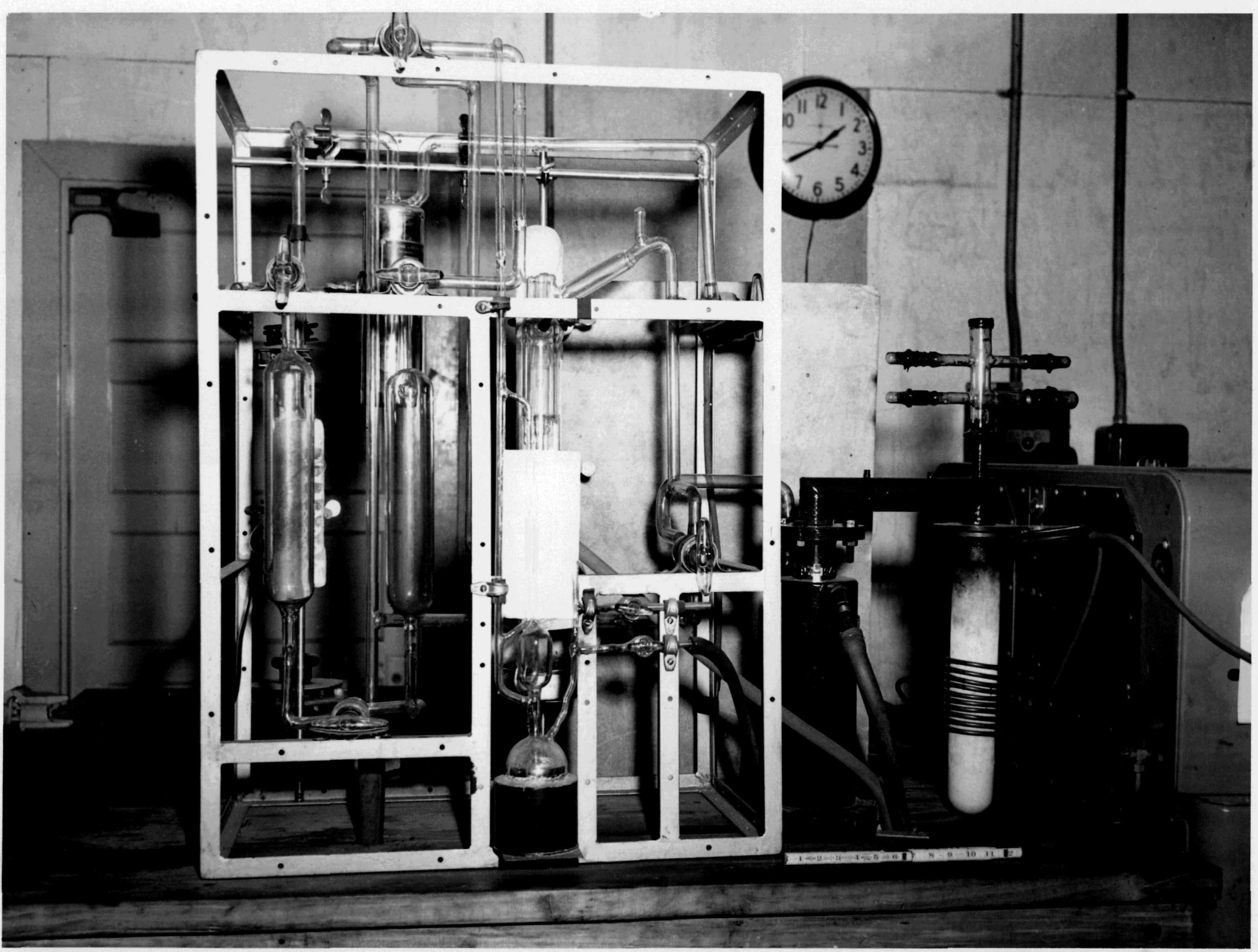




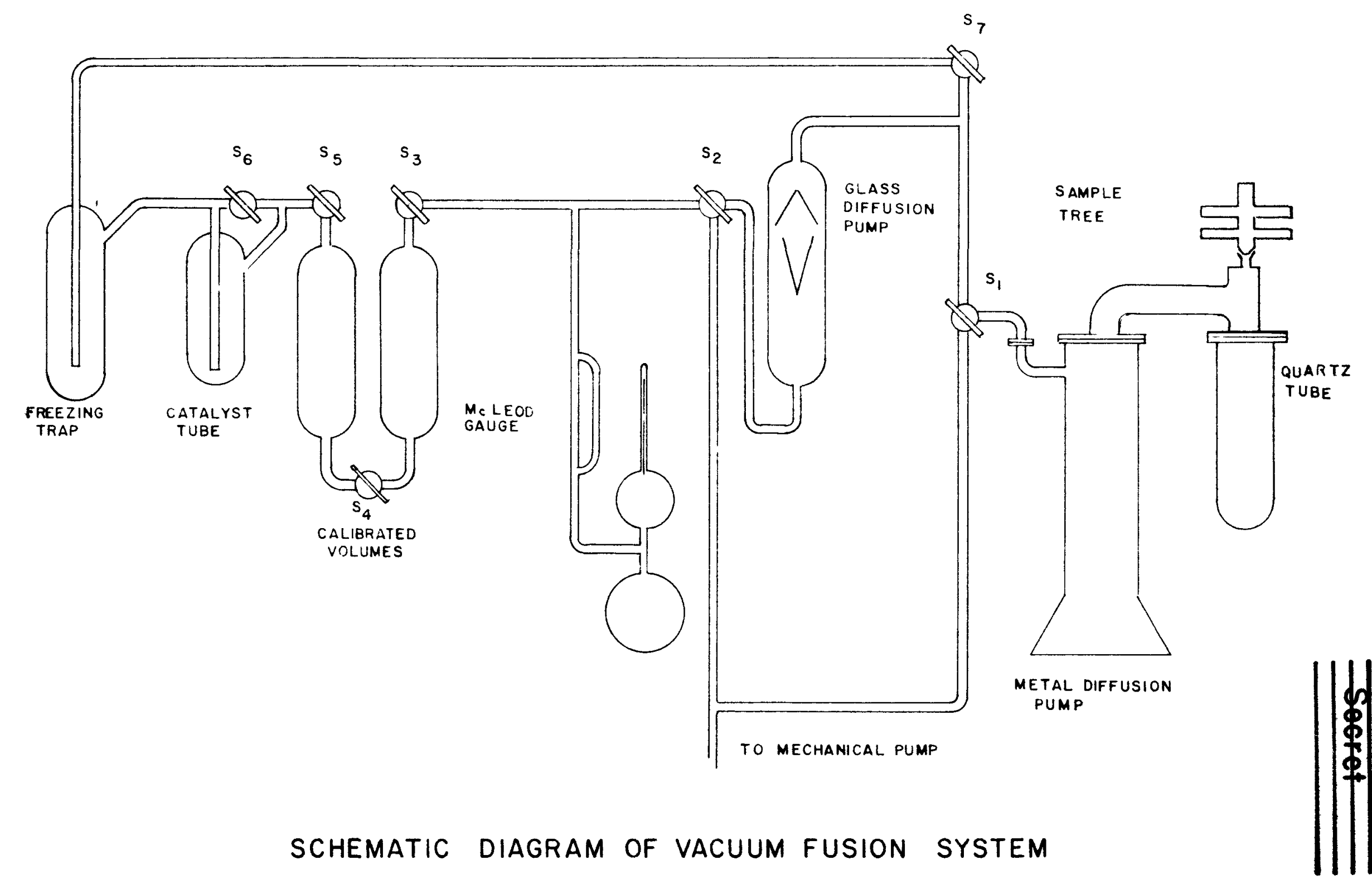

Finura 0 
The rest of the system is used to analyze the evolved gases for hydrogen, carbon monoxide, and hydrogen. This part of the system is all glass and made using $18 \mathrm{~mm} \mathrm{~L}_{\mathrm{w}} \mathrm{D}_{\mathrm{w}}$ glass tubing and stopcocks to permit rapid pumping through the system. The stopcocks are sealed with Dow Corning silicone grease which has given satisfactory performance in keeping leaks from this part of the $8 y s t e m$ to less than 0.2 liter-micron per minute. The gases are pumped into one of three known volumes using D.P.I mercury vapor pump capable of operating against a fore pressure of up to $6 \mathrm{~mm}$. The pressure of the trapped gas is measured with a McLeod gauge calibrated from 0.2-1200 microns. The diffusion pump is also used to circulate the gasen around the system where they are passed over a CuOcatalyst to oxidize the hydrogen to water and the carbon monoxide to carbon dioxide. The gases are then fractionally frozen out using dry ice-acetone and liquid nitrogen. The differences in pressure on collecting the gases in the known volume after each step are used to determine the amounts of hydrogen and carbon monoxide present. The residual gas is assumed to be nitrogen so the final pressure can be used to determine the amount of nitrogen present.

\section{Procedure}

The procedure described below has been adopted for analyzing hydrogen, nitrogen, and oxygen in uranium metal.

Two $10-15 \mathrm{~g}$ samples of uranium metal, previously cleaned with a file and rinsed in acetone, and $50 \mathrm{~g}$ of iron in the form of 1 "pieces of $1 / 4$ " drill rod are loaded in the sample tree. The crucible is mounted in the powdered graphite insulation described above and the system is closed. The system is pumped out very slowly and left with the pump on overnight before the crucible is heated.

The crucible is then heated to $2200^{\circ} \mathrm{C}$ in about $1 \frac{1}{2}$ hours. The long pumping and slow heating are necessary to avoid blowing the graphite powder out by too rapid evolution of gas. After outgassing at $2200^{\circ} \mathrm{C}$ for 3 hours, the crucible is cooled to $1400^{\circ}$ while the iron is dropped and then reheated to the operating temperature of $1750^{\circ} \mathrm{C}$. The iron is outgassed for one hour and a blank is taken. If the blank is less than 6 liter-microns per minute, the gases collected in 15 minutes are analyzed by circulating over the $\mathrm{CuO}$ catalyst at $210^{\circ} \mathrm{C}$ and the dry ice-acetone trap for 10 minutes, collecting in the known volume, measuring the pressure, circulating over the liquid nitrogen trap, collecting in the same volume, and measuring the pressure again. After the system has been pumped out, a sample is dropped, the gases are collected for 15 minutes, and the same analytical procedure as described above is followed. Since each gas collection and analysis requires about 80 minutes, a crucible can be outgassed and two samples analyzed in an 8 hour day.

\section{Preliminary Results}

Difficulties with leaks and high outgassing rates have delayed operation of the apparatus on a routine basis. Several modifications of the original design have been made and leaks have been

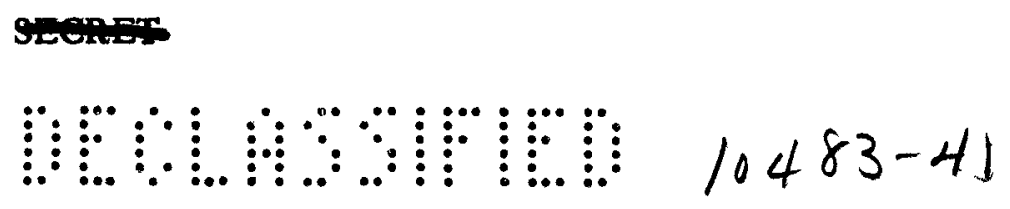


virtually eliminated, but outgassing from the hot crucible and diffusion pump still lead to fairly high blanks ( 5 liter-microns per minute). The reproducibility of results obtained by this apparatus has been checked by analyzing four samples cut from the same portion of an ingot, Sampling errors were reduced by cutting a one inch cube of ingot metal into 24 pieces and selecting three of these pieces at random for each sample. In this series values of $13,12,12$, and $15 p p m$ oxygen were obtained in successive runs. Although this indicates only fair reproducibility, it is expected that it will improve as experience is gained in using the apparatus.

\section{REFERENCES}

1. Guldner, W.G. and Beach, A.L., Anal. Chem. 22, 366, (1950).

2. Lipkin, D. and Perlman, M. Los, MDDC-294.

3. Chipman and Fontana, Ind. Eng. Chem., Anal. Ed., 7, 391, (1950).

4. Horton, W. S., KAPL-666。 


\section{MODIFICATIONS OF THE PYROELECTRIC CONCENTRATION \\ METHOD FOR IMPROVING BORON SENSITIVITY}

by

R. S. Vogel

Introduction

The possibility of production of uranium metal having a boron concentration less than $0.10 \mathrm{ppm}$ necessitates a more sensitive test than is now available.

Aim

An investigation is being made of possible ways to increase the sensitivity of the modified pyroelectric concentration method ${ }^{\mathrm{a}}$ used in this laboratory.

\section{Experimental}

An enhancement of the line-to-background ratio may be accomplished by an exposure period more favorable with respect to boron evolution and by the use of a carrier giving lower background density than gallium oxide in the vicinity of the boron lines. Moving plate studies show boron evolution to be strongest during the first fifteen seconds of arcing time. Longer exposures build up background, thereby diminishing boron sensitivity. Preparations of a sample containing $0.14 \mathrm{ppm} B$ exposed for successively longer periods between 12 and 35 seconds show a systematic decrease of line-to-background ratio.

Indium oxide as a carrier behaves similarly to gallium oxide, but its chief advantage with respect to baton is the absence of any strong lines in the vicinity of 2498 . Trials usiag $\ln _{2} \mathrm{O}_{3}$ show considerably greater boron sensitivity than is obtained using $\mathrm{Ga}_{2} \mathrm{O}_{3}$.

The use of a pelletized electrode charge offers promise by increasing the allowable sample weight by $50 \%$ without increasing background density.

Preliminary trials using a combination of these conditions show a possibility of lowering the limit of detection of boron to less than $0.01 \mathrm{ppm}$. Then the work is completed a report will be made.

${ }^{1}$ Scribner, B. F. and Mullin, H. R. - "A System of Methods for the Spectrochemical Analysis of Uranium-Base Material," A-2907 (Special) (1945). 


\section{R. S. Vogel}

In a previous report, H. R. Mullin of NBL reported the use of a dental analgamator (Wig-L-Bug manufactured by Crescent Dental Manufacturing Company, Chicago, Illinois) to mix previously ground samples with graphite for spectrographic analysis.

At the suggestion of Dr. J. U. Shepardson of MCW an attempt was made to apply the Wig-L-Bug to the grinding of $\mathrm{U}_{3} \mathrm{O}_{8}-\mathrm{Ga}_{2} \mathrm{O}_{3}$ mixtures used in the carrier-distillation method. The Wig-L-Bug is normally supplied with a plastic capsule $\% "$ " 1 " (internal size) and a pestle $\left(3 / 16^{\prime \prime} . \times 3 / 4\right.$ plastic rod having a metallic core for added mass). In use, a rapid reciprocating motion of the capsule containing pestle and sample causes the pestle to strike against the ends of the capsule, thereby reducing the sample to a fine powder in a very short time.

Sample mixtures of $490 \mathrm{mg}^{\mathrm{U}} \mathrm{U}_{2} \mathrm{O}_{4}$ and $10 \mathrm{mg} \mathrm{Ga}_{2} \mathrm{O}_{2}$ ground in a mullite mortar for $2-3$ minutes and mixtures processed by the $\mathbf{W i g}-\mathrm{L}-\mathrm{Bug}$ for an 8-second period showed comparable fineness and uniformity under microscopic examination.

Spectrographic results on sample mixtures prepared by the two methods are listed in Table 1.

\section{Table I}

Comparison of Results Obtained by Grinding in Mullite and in Wig-L-Bug

\begin{tabular}{lcc} 
& \multicolumn{2}{c}{ Preparation } \\
\cline { 2 - 3 } Element & $\begin{array}{l}\text { Ground in } \\
\text { Mullite 2-3 min. }\end{array}$ & $\begin{array}{l}\text { Processed in } \\
\text { Wig-L-Bug 10 sec. }\end{array}$ \\
\cline { 2 - 3 } Al & $<5$ Ppm & $<5$ ppm \\
Bi & $<1$ & $<1$ \\
B & 0.14 & 0.12 \\
Co & $<1$ & $<1$ \\
Cr & 1 & 1 \\
$\mathrm{Cu}$ & $<1$ & 1 \\
$\mathrm{Fe}$ & 15 & 10 \\
In & $<0.1$ & $<0.1$
\end{tabular}




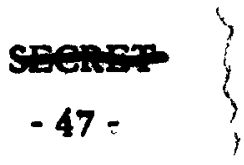

Table 1 (cont'd.)

Preparation

\begin{tabular}{c} 
Element \\
\hline$M_{\mathbf{g}}$ \\
$\mathrm{Mn}_{\mathbf{n}}$ \\
$\mathrm{Mo}$ \\
$\mathbf{N i}$ \\
$\mathbf{P}$ \\
$\mathbf{P b}$ \\
$\mathbf{S b}$ \\
$\mathbf{S i}$ \\
$\mathrm{Sn}$ \\
$\mathbf{V}$ \\
$\mathrm{Zn}$
\end{tabular}

\begin{tabular}{|c|c|}
\hline $\begin{array}{l}\text { Ground in } \\
\text { Mullite 2-3 min. }\end{array}$ & $\begin{array}{l}\text { Processed in } \\
\text { Tig-L-Bug } 10 \text { sec. }\end{array}$ \\
\hline $5 \mathrm{ppm}$ & $5 \mathrm{ppm}$ \\
\hline$<1$ & $<1$ \\
\hline$<5$ & $<5$ \\
\hline 1 & $<1$ \\
\hline$<10$ & $<10$ \\
\hline$<1$ & $<1$ \\
\hline 1 & 1 \\
\hline$<5$ & $<5$ \\
\hline$<1$ & $<1$ \\
\hline$<10$ & $<10$ \\
\hline 10 & 10 \\
\hline
\end{tabular}

In addition to considerable saving of time in the preparation of a large number of samples, the Wig-L-Bug method yields more reproducible results by elimination of variations between operatore. 


\section{THE DETERMINATION OF NITROGEN IN URANIUM METAL}

by

Gerhard P. Lang

\section{Introduction}

Uranium ingots recast under vacuum have been tested for nitrogen on a routine basis for many years by methods developed early in the Manhattan Project. Derbieg, which are the reguluses produced in the thermite reaction which yields uranium metal, have not been tested on a routine basis. However, on occasions, when derby samples have been analyzed, nitrogen values considerably lower than the usual ingot values have been obtained. Any calculation of nittogen pickup in the process between derby and ingot could not account for the difference actually determined. For this reason a restudy of the methods of nitrogen determinations was begun.

The literature (cf. especially eference $i$ and the papers there referred to) indicates thet the method now in use is considered to be adequate for ingors. Howerer, the hydrochloric acid method of solution, which is the one being used, was questioned by $J$. $W$. Stevenson since it is reported $\mathrm{d}^{2}$ that the nitrides of uranium are insoluble in hydrochloric acid. For this reason, improved methods of solution were the chief aim of this investigation.

\section{Experimental}

The method in routine use in this laboratory is that described by Mundy ${ }^{2}$ which employs Neseler's reagent and a Fisher Nesslerimeter for estimating the distilled ammonia.

Variations of this method included the spectrophotometric estimation of the Nesslerized solutiens as described by Wright ${ }^{2}$ and the volume tric estimation of the ammonia as described by Mundy ${ }^{2}$. The methods of solution used were the following:

A. Hydrochloric Acid Method: Ten $\mathrm{ml}$ of $6 \mathrm{M}$ hydrochlotic acid are added to the cleaned sample. $\Lambda$ vigorous reaction results leaving a black fine-grained precipitate. It has been shown that this precipitate does not prevent the distillation of ammonia from the reaction mixture.

B. Hydrochloric AcidHydrogen Peroxide Method: In this method the hydrochloric acid slurty is oxidized with $39 \%$ hydrogen peroxide until complete solution is obtained. Large blanks are obtained in this method. 
C. Hydrochloric AcidPerchloric Acid Method: In this method the hydrochloric acid slurry is oxidized by adding $3.0 \mathrm{ml} 72 \%$ perchloric acid and evaporating to fumes of perchloric acid, at which point complete solution is immediately obtained.

D. Phosphoric Acid Method: The sample is heated with $5 \mathrm{ml} 85 \%$ phosphoric acid until complete solution results. Solution is somewhat slow unless the sample is finely divided. With gramsized samples, the precipitation of gelatinous uranous phosphate on dilution makes the sample difficult to handle.

\section{Determination of Nitrogen in Uranium Nitrides}

In order to test the above procedures on uranium nitrides, several preparations of the nitrides were made by J。W. Sterenson and $R_{0}$ D. Piper of our Research Laboratory。

To prepare uranium sesquinitride $\left(\mathrm{U}_{2} \mathrm{~N}_{3}\right), 200$ grams of uranium metal turnings were heated in nitrogen at $i$ atmosphere in a stainless steel tube. The reaction was followed by observing the pressure of nitrogen in the reaction tube. The temperature of the tube rose to $1000^{\circ} \mathrm{C}$ in about one hour and was held there for approximately another hour before cooling. The gain in weight of the sample corresponded approximately to a product of composition $\mathrm{UN}_{\mathrm{i}_{\sigma}}$.

To prepare uranium mononitride, a second preparation of the sesquinitride was made. From the gain in weight it had a composition corresponding to $\mathrm{UN}_{\mathrm{t}_{0} 4^{\circ}}$ This product was then transferred to a graphite crucible and heated for four hours at $1400^{\circ} \mathrm{C}$ in a high vacuum. The pressure at the start was less than 20 microns of mercury. This rose to $\mathbf{4 0 0}$ microns during the reaction and then slowly fell again but never to the original pressure. The change in weight of the sample during this operation could not be obtained because quantitative transfer could not be made.

It is evident that pure nitrides of a definite composition were not obtained. Since uranium nitrides are easily oxidized, the products probably contained oxides. $\mathbf{A}$ carbon determination on the sample called UN showed that it also contained uranium carbide ( $\underline{v}_{0} \underline{i}_{0}$ ).

Even though these uranium nitride preparations were not suited to a critical test of the above nitrogen procedures, it was possible to obtain qualitative information concerning the ability of these various procedures to determine nitrogen in uranium nitrides.

It can be seen from the qualitative observations on the solubilities of these nitrides in various acids (Table I) that the hydrochloric acid method of solution is inadequate, and that, of the methods tried, those employing perchloric or phosphoric acid are the best.

\section{seencis}

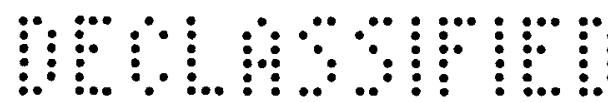


Nitrogen analyses were made on these preparations using various methods of solution and estimation. The uranium analyses listed were performed by means of a ceric sulfate titration method.

On the material called $\mathrm{UN}_{\mathrm{k}, \mathrm{s}}$ an average nitrogen analysis approximating that in $\mathrm{UN}_{\mathrm{su}}$ was obtained (cf. Table II and III), but the uranium analysis is $2.5 \%$ lower than that contained in $\mathrm{UN}_{\mathrm{s}_{0} 3^{\circ}}$ These values correspond fairly closely to a product which is $82.3 \%$ in $\mathrm{U}_{2} \mathrm{~N}_{3}$ and $17.7 \%$ in $\mathrm{U}_{3} \mathrm{O}_{8^{\circ}}$

The sample called UN contained less than half the nitrogen theoretically in this compound. $A$ carbon determination showed the sample to contain $10 \% \mathrm{C}$. This corresponds to $21 \% \mathrm{UC}$, if all carbon is present as UC. The rest of the sample probably consisted of uranium oxides.

\section{Table I}

Solubility of Uranium Nitride Preparations

\begin{tabular}{lll} 
Reagent & $\mathrm{UN}_{i s}$ & UN \\
\hline $\mathrm{HClO}_{4}$ & Soluble & Soluble \\
$\mathrm{H}_{3} \mathrm{PO}_{4}$ & Soluble & Soluble \\
$\mathrm{HCl}$ & Insoluble & Insoluble \\
$\mathrm{HNO}_{3}$ & Mostly soluble。 Leaves & Soluble except for \\
& fine black residue. & slight residue. \\
$\mathrm{HCl}_{-} \mathrm{H}_{2} \mathrm{O}_{2}$ & Partially soluble & Soluble except for \\
& & slight residue
\end{tabular}

Table II

Nitrogen Determinations on Uranium Nitride Preparations

\begin{tabular}{|c|c|c|c|}
\hline $\begin{array}{l}\text { Method of } \\
\text { Solution }\end{array}$ & $\begin{array}{l}\text { Method of } \\
\text { Estimation }\end{array}$ & $\begin{array}{l}\mathrm{UN}_{\boldsymbol{d}_{0} 3} \\
\% \mathrm{~N}\end{array}$ & $\begin{array}{l}U N \\
\% N\end{array}$ \\
\hline $\begin{array}{l}\mathrm{H}_{3} \mathrm{PO}_{4} \\
\mathrm{H}_{3} \mathrm{PO}_{4} \\
\mathrm{H}_{3} \mathrm{PO}_{4} \\
\mathrm{H}_{3} \mathrm{PO}_{4} \\
\mathrm{H}_{3} \mathrm{PO}_{4} \\
\mathrm{H}_{3} \mathrm{PO}_{4} \\
\mathrm{H}_{3} \mathrm{PO}_{4}^{*} \\
\mathrm{HClO}_{4} \\
\mathrm{HClO}_{4} \\
\mathrm{HClO}_{4}^{*} \\
\mathrm{HCl} \mathrm{H}_{2} \mathrm{O}_{2}\end{array}$ & $\begin{array}{l}\text { Volumetric } \\
\text { Volumetric } \\
\text { Volumetric } \\
\text { Volumetric } \\
\text { Volumetric } \\
\text { Volumetric } \\
\text { Volumetric } \\
\text { Volumetric } \\
\text { Spectrophotometric } \\
\text { Spectrophotometric } \\
\text { Volumetric }\end{array}$ & $\begin{array}{l}7.10 \\
6.11 \\
6.35 \\
6.85 \\
7.00 \\
6.94 \\
7.06 \\
6.51 \\
6.25 \\
. \\
6.68\end{array}$ & $\begin{array}{c}2.84 \\
\vdots \\
\vdots \\
\vdots \\
2.85 \\
2.30 \\
2.80 \\
2.20 \\
\text { av. } 2.59\end{array}$ \\
\hline
\end{tabular}

Senes 
Table III

Comparison of Determinations $w$ ith Theoretical Values

\begin{tabular}{|c|c|c|}
\hline & $\% \mathbf{N}$ & $\% \mathrm{U}$ \\
\hline Theory for $\mathrm{UN}_{1,3}$ & 7.10 & 92.90 \\
\hline Found for $\mathrm{UN}_{1,3}$ & $a v_{\circ} 6.68$ & 90.40 \\
\hline Theory for UN & 5.56 & $94: 44$ \\
\hline Found for UN & av. 2.59 & 93.40 \\
\hline
\end{tabular}

The results in Table III indicate that if the nitrogen is present as uranium nitride, our routine method, which uses hydrochloric acid solution, would not be adequate, whereas the phosphoric acid and perchloric acid methods provide a more nearly correct result

\section{Determination of Nitrogen in Derbies}

Derbies are sampled by sawing a section $3-5 \mathrm{~mm}$ in width through a diameter of the derby and punching approximately $2 \mathrm{~g}$ samples from this slice. In order to determine the distribution of nitrogen in a derby, punches were taken at various places in the slice, and these samples were numbered as in Figure 1 .

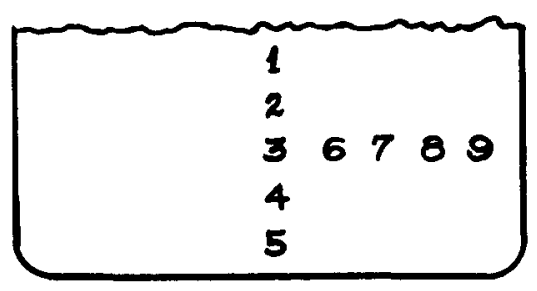

Figure 1.

The results of the hydrochloric and perchloric acid methods are shown in Table IV. The ammonia was estimated by the spectrophotometric method. It is very evident that the hydrochloric acid method fails completely for derbies. This probably means that the nitrogen is present in derbies largely as uranium nitrides which are insoluble in hydrochloric acid. It is

\section{SEARET}


also evident that the nitrogen is very inhomogeneously distributed through the derby, and adequate sampling is a major problem.

\section{Table IV}

\section{Nitrogen Determinations on Derbies}

$\mathrm{HClO}_{4}$ Method

Nitrogen in p.p.m. from Location

\begin{tabular}{lllllllll}
\hline 1 & 2 & 3 & 4 & 5 & 6 & 7 & 8 & 9
\end{tabular}

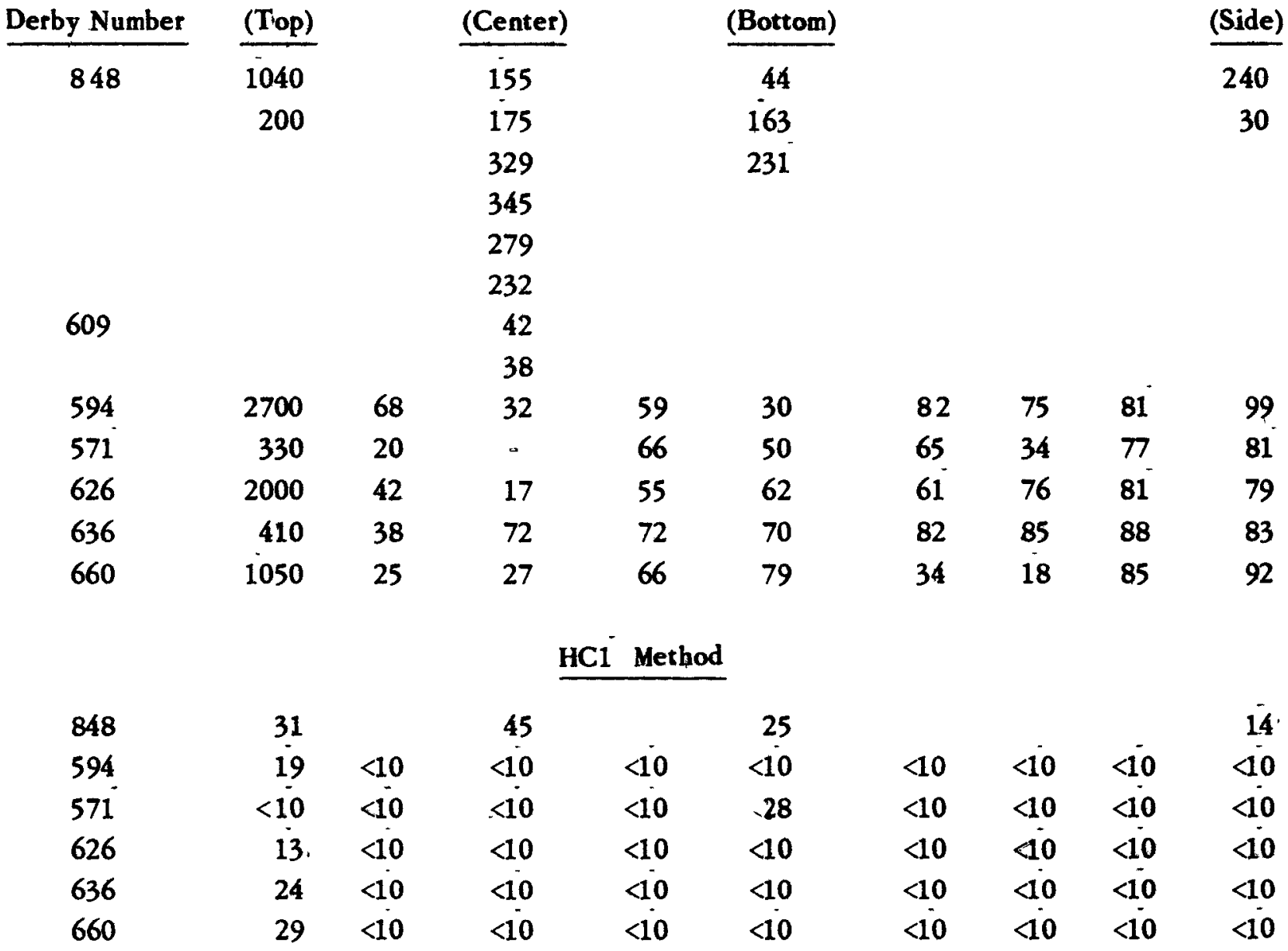


Determination of Nitrogen in Ingots

Furman, Mundy and Wolf",s have shown that the hydrochloric acid method and the hydrochloric acid-hydrogen peroxide method give the same results on ingot samples. Using a standard ingot sample, which is analyzed periodically to keep a running check on nitrogen determinations in this laboratory, it has been found that there is no difference between the hydrochloric acid and the perchloric acid methods.

Table V

Determination of Nitrogen on a Standard Ingot Sample

\begin{tabular}{|c|c|c|c|}
\hline Method & $\begin{array}{c}\text { Number of } \\
\text { Determinations }\end{array}$ & Average (ppm) & $\begin{array}{l}\text { Precision at the } \\
95 \% \text { Confidence Level (ppm) }\end{array}$ \\
\hline $\mathrm{HC}_{1}$ & 75 & 39 & \pm 7 \\
\hline $\mathrm{HClO}_{4}$ & 14 & 41 & \pm 5 \\
\hline
\end{tabular}

A comparison between ingots and top crops was also made. Top crops are the top one to two inches of a uranium casting which are remored before it is designated as an ingot. The first two columns of Table VI show the difference between the two methods on ingot and top crop samples taken from the same casting. The nitrogen values on top crops are generally higher. Also, the perchloric acid method gives higher results than the hydrochloric acid method on top crops. The values in the last two columns were obtained by dissolving samples in hydrochloric acid, separating the precipitate by centrifuging and determining nitrogen on the two fractions by the perchlotic acid method. The separation of the precipitate was not entirely complete due to its very fine nature.

Table VI

Comparison of Nitrogen in Ingot and Top Crop Samples

\begin{tabular}{|c|c|c|c|c|}
\hline \multirow[b]{2}{*}{ Sample No. } & \multirow{2}{*}{$\begin{array}{c}\text { HCi } \\
\text { Method, ppm } \\
\end{array}$} & \multirow{2}{*}{$\begin{array}{c}\mathrm{HCiO}_{4} \\
\text { Method, ppm } \\
\end{array}$} & \multicolumn{2}{|c|}{ HC1O, Method } \\
\hline & & & Filtrate, ppm & Precipitate, ppm \\
\hline 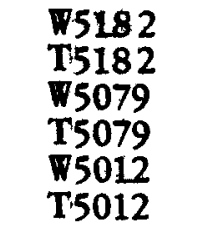 & $\begin{array}{r}65 \\
157 \\
62 \\
42 \\
9, .9 \\
16\end{array}$ & $\begin{array}{r}58 \\
>400 \\
54 \\
190 \\
8 \\
10\end{array}$ & $\begin{array}{r}69 \\
150 \\
56 \\
67 \\
18 \\
15\end{array}$ & $\begin{array}{r}0 \\
240 \\
4 \\
74 \\
8 \\
5\end{array}$ \\
\hline $\begin{array}{l}\mathbf{W} \text { - indicat } \\
\mathbf{T}-\text { indicat }\end{array}$ & & & & \\
\hline
\end{tabular}


Here again the hydrochloric acid method is adequate for ingot samples but not for top crop samples, because hydrochloric acid does not completely dissolve the nitrogen compounds contained in the top crop. The anomolous results of sample 5012 may be due to contamination, or to a variation of nitrogen content within sample slices.

There is a possibility that ingot samples which have a high (greater than 60ppm) nitrogen content may give falsely low values by the hydrochloric acid procedure. This possibility will be investigated.

Summary

Since uranium nitrides are insoluble in hydrochloric acid, any nitrogen analysis which is performed on materials containing nitrides and which utilizes hydrochloric acid alone as solvent will fail. Although no ideal standards have been available for checking, dissolution in perchloric or phosphoric acid was shown to yield a more nearly correct answer. Very low results with hydrochloric acid and higher tesults with perchloric acid on derby metal indicate the apparent presence of uranium nitrides and the impracticability of using hydrochloric acid on derbies. There is some evidence to indicate the possibility of nitride presence also in the tops of ingors.

\section{References}

${ }^{1}$ Rodden, Analytical Chemistry of the Manhatten Project, McGraw Hill Book Co., Inc., N.Y.,(1950)

${ }^{2}$ Katz and Rabinowitch, The Chemistry of Uranium-Part I., McGraw Hill Book Co., Inc., N.Y.,(1951)

- Wright, "Determination of Ammonia and Nitrate Nitrogen Present in Uranyl Sulfate and Uranium Oxides $\bar{s}, Y-919$ (1951)

"Mundy and Wolfe, "A Simplified Method for Determining Nitrogen in the Metal", FCL PN (1943)

s Mundy, "A Critical Study of the Source of Loss of Nitrogen in the Modified Micro Kjeldahl Method", FCLPN (1943) 